\title{
Cooperating with the future
}

\author{
Oliver P. Hauser ${ }^{*}$, David G. Rand ${ }^{2,3^{*}}$, Alexander Peysakhovich ${ }^{1,2}$, Martin A. Nowak ${ }^{1 \dagger}$ \\ ${ }^{1}$ Program for Evolutionary Dynamics, Harvard University, Cambridge, MA 02138 \\ ${ }^{2}$ Department of Psychology, ${ }^{3}$ Department of Economics, Yale University, New Haven, CT 06511 \\ * These authors contributed equally to this work. \\ † To whom correspondence should be addressed. E-mail: martin_nowak@harvard.edu
}

Overexploitation of renewable resources today has a high cost on the welfare of future generations $^{1-5}$. Unlike in other public goods games ${ }^{6-9}$, however, future generations cannot reciprocate actions made today. What mechanisms can maintain cooperation with the future? To answer this question, we devise a new experimental paradigm, the 'Intergenerational Goods Game'. A line-up of successive groups (generations) can each either extract a resource to exhaustion or leave something for the next group. Exhausting the resource maximises the payoff for the present generation, but leaves all future generations empty-handed. Here we show that the resource is almost always destroyed if extraction decisions are made individually. This failure to cooperate with the future is driven primarily by a minority of individuals who extract far more than what is sustainable. In contrast, when extractions are democratically decided by vote, the resource is consistently sustained. Voting ${ }^{10-15}$ is effective for two reasons. First, it allows a majority of cooperators to restrain defectors. Second, it reassures conditional cooperators ${ }^{16}$ that $^{-}$ their efforts are not futile. Voting, however, only promotes sustainability if it is binding for all involved. Our results have implications for policy interventions designed to sustain intergenerational public goods.

Providing for future generations is central to the survival of genes, families, organizations, nations and the global ecosystem ${ }^{1-5}$. Yet providing for the future poses a challenge, as it requires making sacrifices today. Institutions can play an important role in promoting such cooperative behaviour among large groups of people. Traditionally, institutional designers have assumed that people are rational and purely self-interested, and proposed incentives that induce selfish people to cooperate ${ }^{17-19}$.

In recent years, however, a large body of evidence has demonstrated that many people are not purely selfish ${ }^{5,20-25}$. Here we consider the implications of these 'social preferences' for designing institutions that promote sustainability and intergenerational cooperation. We demonstrate that democracy can be a powerful institution for harnessing social preferences: while selfish people would vote for over-exploitation of resources, voting allows a prosocial majority to override a selfish minority. (See Supplementary Information, SI, Section 1 for further motivating discussion.)

To do so, we introduce a laboratory model of cooperating with the future - the Intergenerational Goods Game (IGG) - that builds on previous work using Public Goods Games ${ }^{7-9}$, Common Pool Resource games $^{6,11}$ and Threshold games ${ }^{4,26,27}$. In these other games, selfishness creates social efficiency losses for the other members of one's group. In contrast, the IGG is designed such that selfishness instead negatively impacts subsequent groups. 
In our IGG experiments, individuals form groups of five, which we refer to as generations. The first generation is endowed with a common pool of 100 units and each individual can extract between 0 and 20 units from the pool. If the total percentage of units extracted from the pool is at or below a commonly known extraction threshold, $T$, the pool will renew to 100 units for the next generation. If, however, the percentage extracted is above $T$, the pool is exhausted and all future generations receive no payoff (Figure 1). After each generation, another generation occurs with probability $\delta$, and with probability $1-\delta$ the game ends: the discount factor $\delta$ models the extent to which the current generation values the next generation. (See SI Section 2 for further experimental details.)

In the game theoretic tradition, the IGG framework is a great simplification relative to real-world intergenerational cooperation. For discussion of important aspects of intergenerational transfer which the IGG does yet not incorporate, as well as relation of our work to previous results on intergenerational transfer, see SI Section 3.

To explore behaviour in the IGG, we begin with an 'unregulated' treatment: each group member individually chooses how many units to extract from the pool. We initialize 20 unregulated IGGs, and pass each game's pool across a series of generations with a discount factor of $\delta=0.8$ (leading to an expected game length of five generations). For the pool to be replenished, each generation must extract 50 units or less $(T=50 \%)$. Thus the socially efficient extraction (or 'fair share') is 10 units per individual on average. We focus on symmetric strategies and refer to individuals who extract 10 or fewer units as cooperators, and those who extract more than 10 units as defectors.

We find that a large majority of individuals cooperate $(68 \%)$, in line with previous studies using non-student populations ${ }^{23-25}$. Despite their good intentions, however, only 4 of the 18 games continuing on to a second generation have their pools sustained. These losses in sustainability compound quickly over time: in generation 3 , the number of refilled pools is down to two, and not a single refilled pool is available to the 4th generation (Figure 2a). Notably, in most groups, only a minority of defectors is responsible for the exhaustion of the resource.

To address this sustainability failure, we introduce an institution that is central to the Western world: democracy. Each group member votes for their generation's extraction level, and the median vote is extracted by all players. Well studied by economists and political scientists ${ }^{10-15}$, this 'median voting' rule guarantees socially optimal outcomes in a standard Public Goods Game, even with perfectly self-interested actors: the payoff-maximising vote is full cooperation $^{14,15}$. In the IGG, however, this is not true: because the current group does not reap the benefits of cooperation, selfish players would vote to deplete the resource fully. From a traditional 'public choice' perspective based on rational self-interest, therefore, median voting is not attractive for promoting sustainability. If, however, enough players have social preferences, voting may be able to support sustainability in the IGG by allowing prosocial players to reign in selfish players. Thus a 'behavioural public choice theorem ${ }^{12-14}$ might favour median voting; see SI Section 1 for further discussion. 
To explore the effects of median voting, we initialize another 20 IGGs using $\delta=0.8$ and $T=50 \%$, and applied the voting rule. We find a dramatic increase in sustainability (Figure 2b): all 20 common pools are sustained across all generations (unregulated vs. voting: linear probability model (LPM) predicting pool sustainability at the generation level, $p<0.001$; see SI Section 4 for statistical details).

Next we ask how robust the voting mechanism is to variation in the discount factor, $\delta$, and the extraction threshold, $T$. In the experiments described above, there was an $80 \%$ chance that a future generation would exist $(\delta=0.8)$ and individuals had to sacrifice half of their possible payoff to extract a 'fair share' $(T=50 \%)$. We now examine the effectiveness of voting in two treatments using lower $\delta$ values ( $\delta=0.7$ and $\delta=0.6$, creating fewer future generations), and two other treatments using lower $T$ values ( $T=40 \%$ and $T=30 \%$, leading to a higher cost of cooperation). Each treatment again started with 20 pools.

We find that voting remains largely effective in promoting sustainability under these more adverse conditions (Figure 2c). Although sustainability does vary significantly with $\delta$ (LPM, $p=0.037)$ and $T(\mathrm{LPM}, p<0.001)$, the size of these effects is relatively small: decreasing $\delta$ or T by 0.1 decreases the probability of a pool being sustained by $4.6 \%$ or $14.6 \%$, respectively. Moreover, under all conditions tested, voting leads to much higher levels of sustainability than the original unregulated IGG (LPM, $p<0.001$ for all comparisons).

The success of voting is driven by two factors. First, the decision-making power differs in the voting and unregulated institutions (Figure $3 \mathrm{a}$ ). In the voting institution, a majority of three cooperators who propose 10 unit extractions can overrule two defectors who propose 20 units. In contrast, if decisions are made at the individual level, a single defector can tip the balance of a group. In other words, voting allows a majority of cooperators to restrain a minority of defectors.

The second reason for the success of voting pertains to the psychology of social preferences. Median voting addresses the fears of players who care about future generations but worry that others (now or later) will exhaust the pool (i.e., future-oriented 'conditional cooperators' ${ }^{16}$ ): since the outcome of the vote is applied to all players, everyone within a generation receives the same payoff and no one risks being the 'sucker'. This, in turn, further increases the probability that a cooperative majority is formed and the pool is sustained, both in the current generation and in the future. Figure $3 \mathrm{~b}$ is consistent with this assessment: the fraction of cooperators is $20 \%$ larger under voting than unregulated (LPM coef $=0.201, p<0.001)$.

Both of these factors predict that voting is only successful if everyone is bound by the outcome: a partial implementation ${ }^{15}$ provides an opportunity both for defectors to derail sustainability, and for potential cooperators to switch to defection out of fear that others will over-exploit.

We test this prediction by introducing a 'partial voting' treatment (another 20 pools, again using $\delta=0.8$ and $T=50 \%$ ). Three of the five people in each generation are bound by the decision of a median vote among themselves. The other two people are not informed of the vote's outcome, and decide freely how much to extract. The sum of all five extractions is then compared to the extraction threshold $T$. 
As predicted, the partial voting institution is significantly less successful than the full voting institution (Figure 4a, LPM $p<0.001$ ). This point is driven home by bootstrapping simulations: of 10,000 pools created by randomly sampling participant decisions each generation, only $1.5 \%$ of available pools are sustained after 15 generations under partial voting, compared to $84 \%$ under full voting; see Extended Data Figure 1 and SI Section 5 for details. We conclude that, for voting to effectively manage sustainability, it must be binding for all decision-makers.

In this paper, we have introduced a new laboratory model for cooperation across generations, the Intergenerational Goods Game (IGG). We have shown that in the absence of regulation, a minority of selfish players consistently deplete available resources. By implementing median voting, however, this negative outcome can be prevented - but only if all players are bound by the outcome of the vote. Votes that are only partially binding, such as the international Kyoto protocol, have little power.

More generally, our results emphasize the importance of institutional designers moving away from the assumption of universal self-interest. We extend the 'behavioural public choice theorem, ${ }^{12-14}$ by demonstrating how voting can allow a majority of prosocial individuals to override a purely selfish minority, leading to costly group-level cooperation with future generations. Real-world data are consistent with this suggestion: countries that are more democratic also have more sustainable energy policies (combining data for 128 countries from the Economist's Democracy Index and World Energy's Energy Sustainability Index, $p<0.001$, $R^{2}=0.36$; robust to controlling for GDP, Gini index, population size, literacy rate, unemployment rate, life expectancy, and level of corruption; see Extended Data Figure 2 and SI Section 6 for details). Policy makers can do much to promote the public good by using a behavioural approach that is informed by a more accurate understanding of human psychology ${ }^{14,28-30}$. Many citizens are ready to sacrifice for the greater good. We just need institutions that help them do so. 


\section{References}

1 Hardin, G. The Tragedy of the Commons. Science 162, 1243-1248 (1968).

2 Ostrom, E. Governing the commons: The evolution of institutions for collective action. (Cambridge Univ Pr, 1990).

3 Levin, S. A. Fragile dominion: complexity and the commons. (Basic Books, 2000).

$4 \quad$ Milinski, M., Semmann, D., Krambeck, H. J. \& Marotzke, J. Stabilizing the earth's climate is not a losing game: supporting evidence from public goods experiments. Proc Natl Acad Sci USA 103, 3994-3998, doi:0504902103 [pii] 10.1073/pnas.0504902103 (2006).

5 Wade-Benzoni, K. A. \& Tost, L. P. The egoism and altruism of intergenerational behavior. Personality and Social Psychology Review 13, 165-193 (2009).

6 Ostrom, E., Walker, J. \& Gardner, R. Covenants With and Without a Sword: SelfGovernance is Possible. The American Political Science Review 86, 404-417 (1992).

7 Milinski, M., Semmann, D., Bakker, T. C. M. \& Krambeck, H.-J. r. Cooperation through indirect reciprocity: image scoring or standing strategy? Proceedings of the Royal Society of London. Series B: Biological Sciences 268, 2495-2501, doi:10.1098/rspb.2001.1809 (2001).

8 Fehr, E. \& Gächter, S. Altruistic punishment in humans. Nature 415, 137-140 (2002).

9 Rand, D. G., Dreber, A., Ellingsen, T., Fudenberg, D. \& Nowak, M. A. Positive Interactions Promote Public Cooperation. Science 325, 1272-1275 (2009).

10 Holcombe, R. G. The median voter model in public choice theory. Public Choice 61, 115-125 (1989).

11 Walker, J. M., Gardner, R., Herr, A. \& Ostrom, E. Collective choice in the commons: Experimental results on proposed allocation rules and votes. The Economic Journal 110, 212-234 (2000).

12 Ertan, A., Page, T. \& Putterman, L. Who to punish? Individual decisions and majority rule in mitigating the free rider problem. European Economic Review 53, 495-511 (2009).

13 Putterman, L., Tyran, J.-R. \& Kamei, K. Public goods and voting on formal sanction schemes. Journal of Public Economics 95, 1213-1222 (2011).

14 Kamei, K., Putterman, L. \& Tyran, J.-R. State or nature? Formal vs. informal sanctioning in the voluntary provision of public goods. Experimental Economics (In press).

15 Bernard, M., Dreber, A., Strimling, P. \& Eriksson, K. The subgroup problem: When can binding voting on extractions from a common pool resource overcome the tragedy of the commons? Journal of Economic Behavior \& Organization 91, 122-130 (2013).

16 Fischbacher, U., Gächter, S. \& Fehr, E. Are people conditionally cooperative? Evidence from a public goods experiment. Economics Letters 71, 397-404 (2001).

17 Coase, R. H. The problem of social cost. Journal of Law and Economics 3, 1 (1960).

18 Mueller, D. C. Public choice. (Cambridge University Press Cambridge, 1979).

19 Williamson, O. E. The economic intstitutions of capitalism. (Simon and Schuster, 1985).

20 Forsythe, R., Horowitz, J. L., Savin, N. E. \& Sefton, M. Fairness in Simple Bargaining Games. Games and Economic Behavior 6, 347-369 (1994).

21 Camerer, C. F. Behavioral game theory: Experiments in strategic interaction (Princeton University Press, 2003). 
22 Charness, G. \& Rabin, M. Understanding Social Preferences with Simple Tests. Quarterly Journal of Economics 117, 817-869 (2002).

23 Fosgaard, T., Hansen, L. G. \& Wengström, E. Framing and misperceptions in a public good experiment. Institute for Food and Resource Economics Working Paper (2011).

24 Amir, O., Rand, D. G. \& Gal, Y. K. Economic Games on the Internet: The Effect of \$1 Stakes. PLoS ONE 7, e31461, doi:10.1371/journal.pone.0031461 (2012).

25 Rand, D. G., Greene, J. D. \& Nowak, M. A. Spontaneous giving and calculated greed. Nature 489, 427-430 (2012).

26 Jacquet, J. et al. Intra-and intergenerational discounting in the climate game. Nature Climate Change (2013).

27 Cadsby, C. B. \& Maynes, E. Gender and free riding in a threshold public goods game: Experimental evidence. Journal of economic behavior \& organization 34, 603-620 (1998).

28 Oullier, O. Behavioural insights are vital to policy-making. Nature 501, 463-463 (2013).

29 Benkler, Y. The penguin and the leviathan: How cooperation triumphs over self-interest. (Random House LLC, 2011).

30 Haynes, L., Service, O., Goldacre, B. \& Torgerson, D. Test, learn, adapt: developing public policy with randomised controlled trials. Cabinet Office - Behavioural Insights Team. Available at SSRN: http://Ssrn.com/abstract=2131581 (2012).

\section{Acknowledgements}

We thank Anna Dreber for discussion and three anonymous reviewers for helpful feedback. Financial support from the Department of Organismic and Evolutionary Biology at Harvard, the Harvard Office for Sustainability and the John Templeton Foundation is gratefully acknowledged.

\section{Author contributions}

O.H., D.R., A.P. and M.N. designed and performed the experiments, analysed the data and wrote the paper.

\section{Competing financial interests}

The authors declare no competing financial interests. 


\section{Figure Legends:}

Figure 1. An illustration of the intergenerational game (IGG): In each generation, a group of 5 people makes a decision (individually or according to an institutional rule) about their level of extraction from a common resource. a, If Generation 1's extractions do not violate the commonly known threshold, the resource refills and the same dilemma is presented to Generation 2. After each generation, another generation occurs with probability $\delta$. b. If at any point the threshold requirement is not met, the resource does not renew and future generations receive no payoff. Maximal social welfare is achieved if no generation ever violates the threshold requirement by extracting too much from the common resource.

Figure 2. Solving the (intergenerational) tragedy of the commons through an institutional design. a, When decisions are made at the individual level, the availability of the common pools drastically decreases over time; $N=480$. b. The introduction of a democratic voting institution dramatically improves sustainability; $N=370$. c, Decreasing the discount factor from $\delta=0.8$ to $\delta=0.7(N=355)$ or $\delta=0.6(N=305)$ while holding $T=50 \%$, or the extraction threshold from $T=50 \%$ to $T=40 \%(N=600)$ or $T=30 \%(N=460)$ while holding $\delta=0.8$, increases the temptation to defect. Nonetheless, much less is extracted under median voting compared to the unregulated baseline. Errors bars indicate standard errors of the mean.

Figure 3. The voting institution is robust to extreme decision-makers and thereby increases cooperative behaviour. a, The pivotal decision-maker in the voting institution is different from the unregulated institution. For instance, assume that $T=50 \%$, and that a cooperator and a defector always extract 10 and 20 units, respectively. The unregulated institution is vulnerable to extreme decision-makers, whereas the voting institution is robust to a minority of defectors. This, in turn, bolsters the decision of those who are predisposed towards cooperation but fear to be exploited (e.g., future-oriented 'conditional cooperators'). b, This leads to an increase of cooperators in the voting institution $(N=370)$ over the unregulated institution $(N=480)$.

Figure 4. We confirm the hypothesis that voting must be binding for all players to achieve high levels of sustainability. a, In a partially implemented voting institution $(N=495)$, three of the individuals are bound to a vote while the other two can extract at will. A partially implemented voting institution is not robust to a minority of defectors and also cannot reassure conditional cooperators. Thus, partial voting fails to lead to sustainable outcomes. $\mathbf{b}$, Three real sets of decisions from our data demonstrate a consequence of the pivotal extractor outside the voting group.

Extended Data Figure 1. Bootstrapping simulations demonstrate the robustness of full voting, and the failure of partial voting. We address sources of noise in the sequence of events that occurred in our experiment by conducting a set of computer simulations using the data generated by our participants. We randomly sample (with replacement) a series of generations of participant decisions, and calculate the fraction of those generations in which the pool was refilled. For each condition, we simulate 10,000 pools (or $1,000,000$ pools if $\delta<0.8$ ) for 15 generations. a, Simulated data for the unregulated, full voting and partial voting conditions show that the voting is by far the most successful at sustaining the pool. $\mathbf{b}$, Simulated data for the $T=40 \%, T=30 \%, \delta=0.7$ and $\delta=0.6$ conditions shows that reducing $\delta$ has only a small effect, and 
although reducing $T$ does undermine sustainability, the effect is much less dramatic than that of unregulated or partial voting despite the higher value of $T$ in these less-regulated conditions.

\section{Extended Data Figure 2. Real-world data support our experimental conclusions, as} countries with more democratic governments have more sustainable energy policies. Energy sustainability index (as measured by World Energy) is shown as a function of the Democracy Index (as measured by the Economist's Intelligence Unit) for $N=128$ countries. A strong positive association is clearly visible, and this association is robust to controlling for gross domestic product (GDP), Gini index, population size, literacy rate, unemployment rate, life expectancy, and level of corruption. Thus we provide preliminary empirical support for the role of democracy in promoting sustainability outside the laboratory. We adopt the colouring and naming scheme from the Economist Intelligence Unit's classification of regimes. 


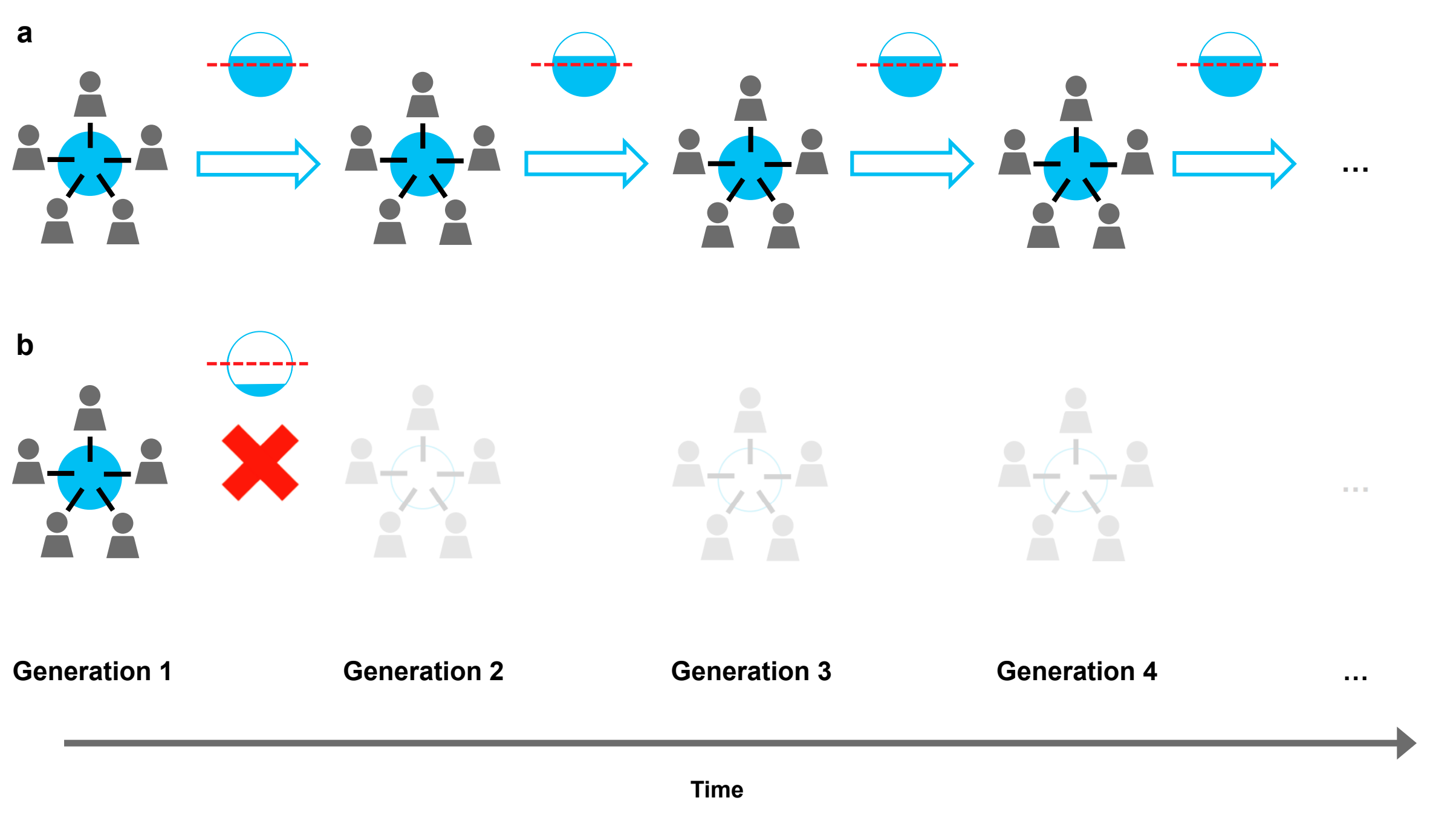




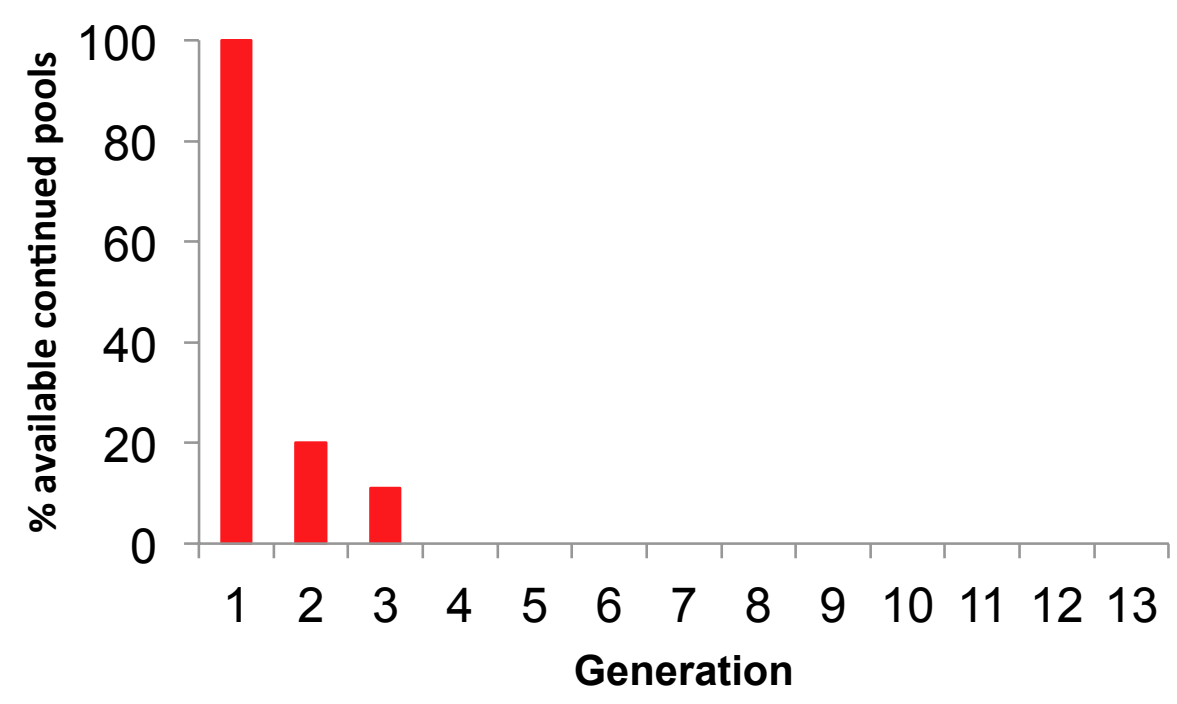

b

Voting
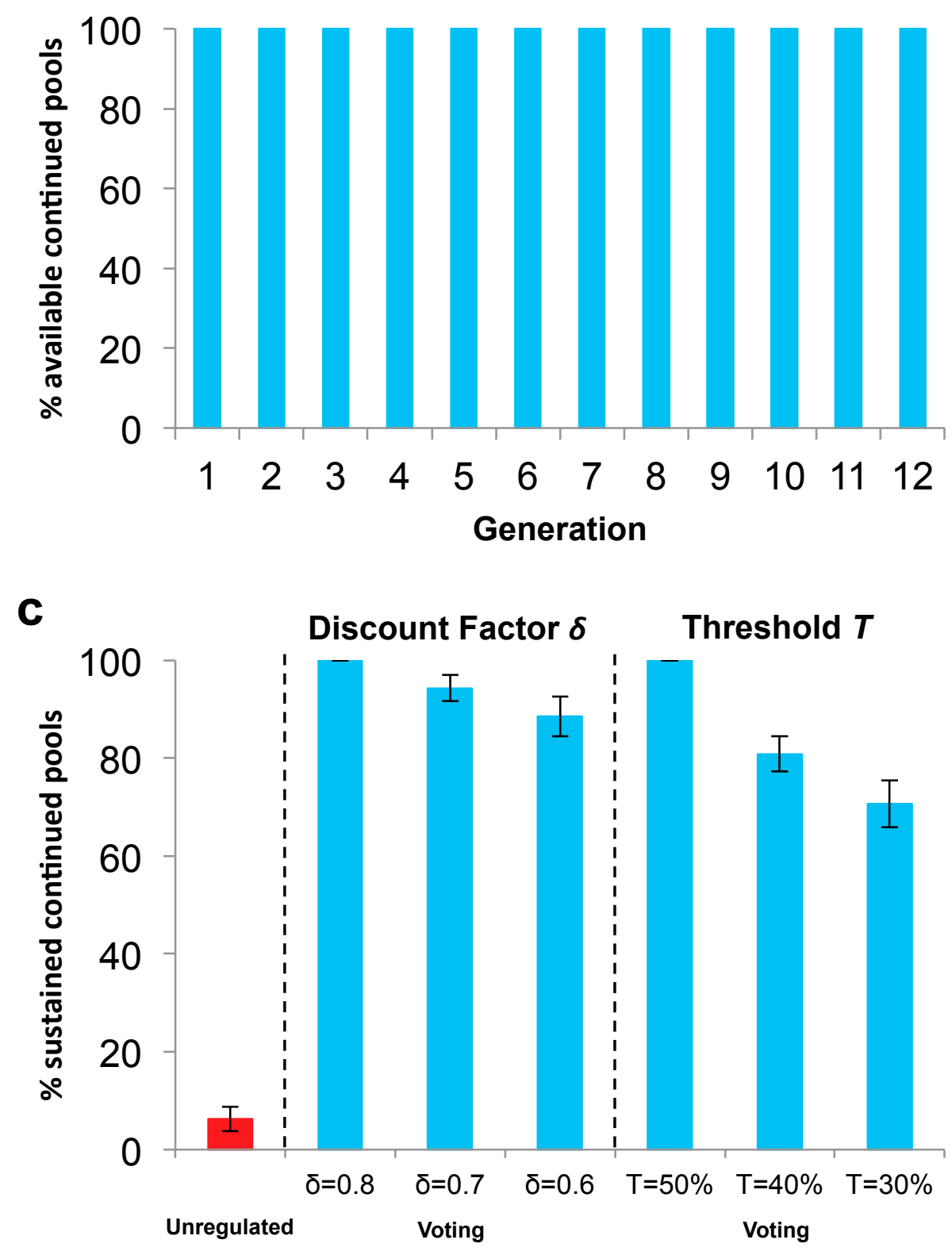


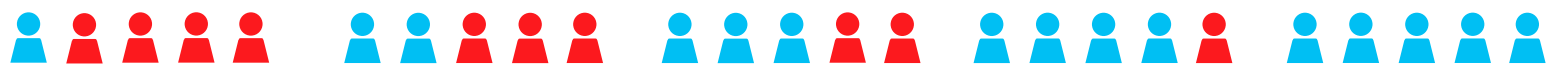

\section{Unregulated}
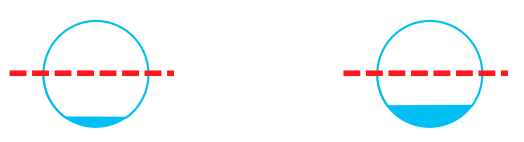

Voting
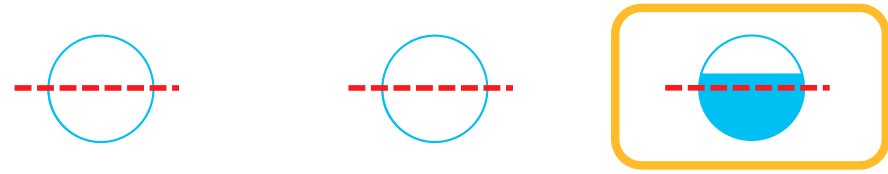
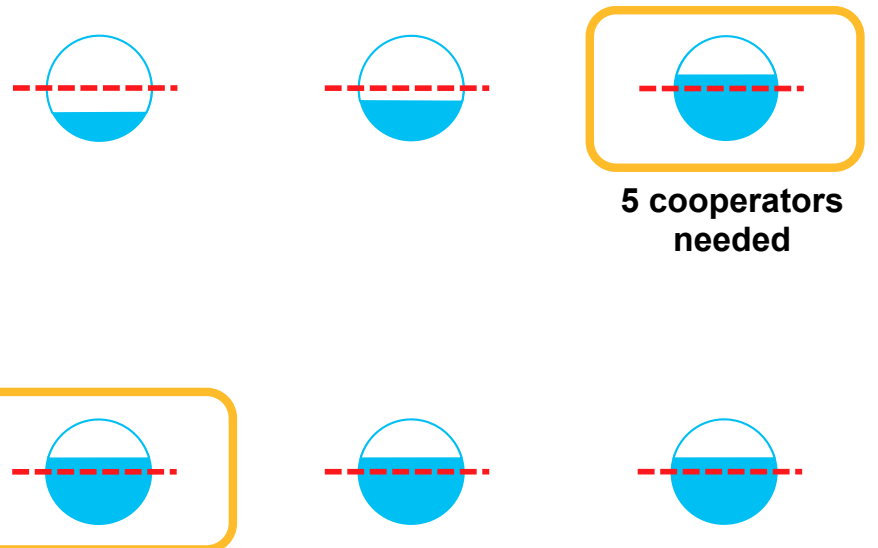

5 cooperators needed

3 cooperators needed
Defectors
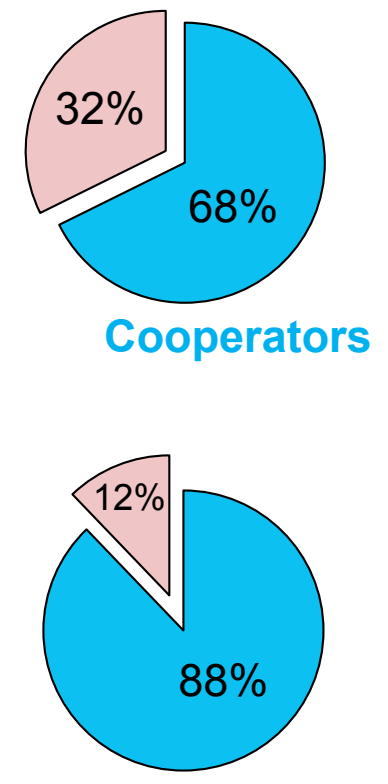
a

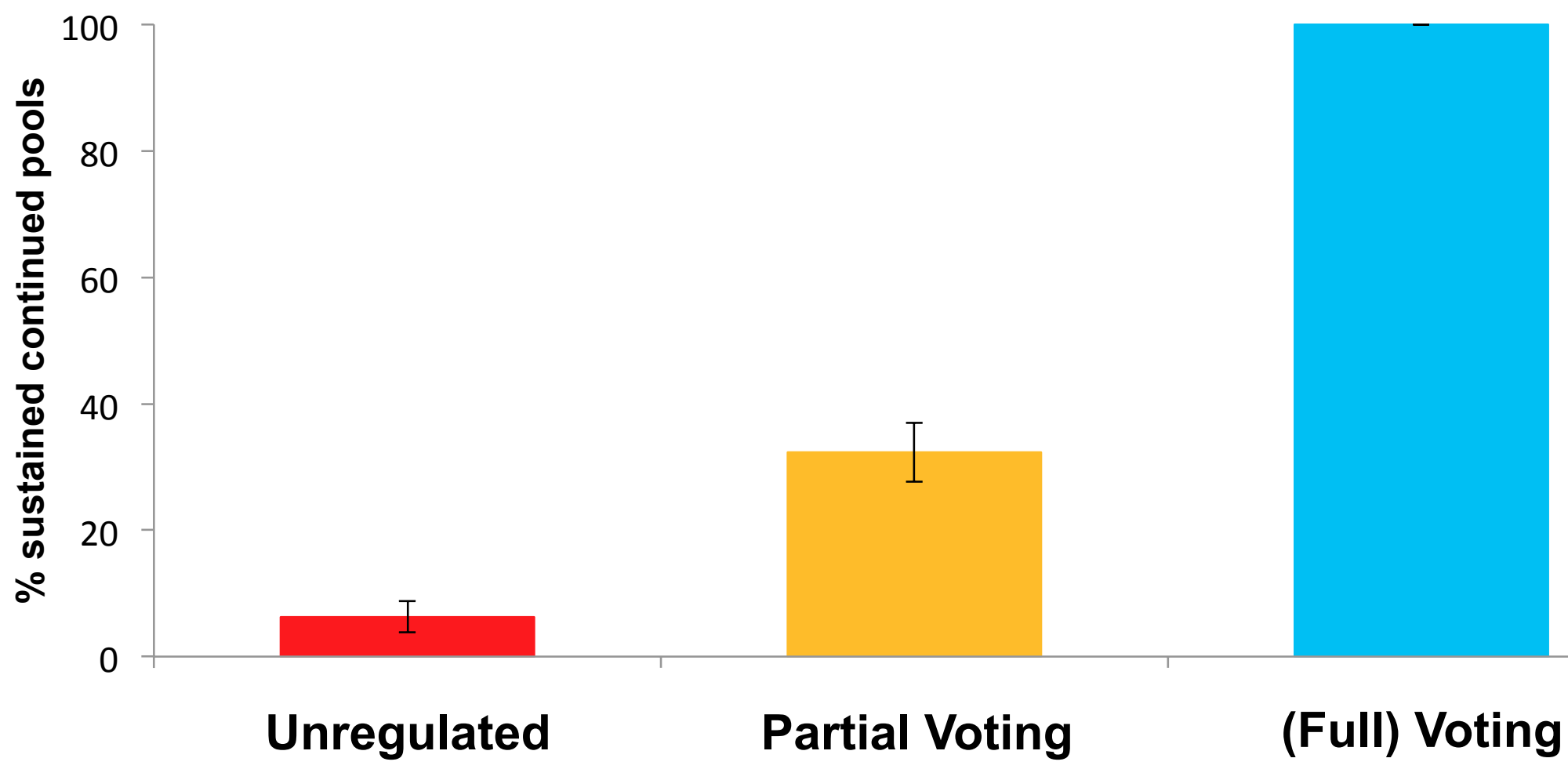

b

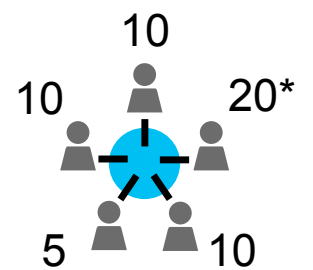

Total extractions: 55 units

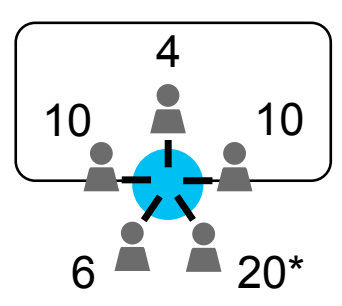

Total extractions:

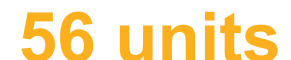

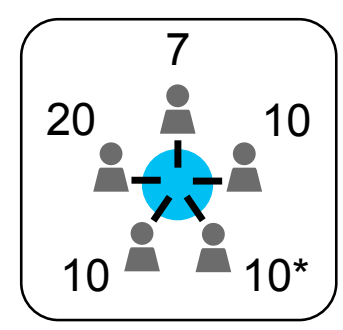

Total extractions: 50 units 


\title{
Supplementary Information
}

\author{
for \\ Cooperating with the future
}

Oliver P. Hauser*, David G. Rand*, Alexander Peysakhovich, Martin A. Nowak

\section{Table of Contents:}

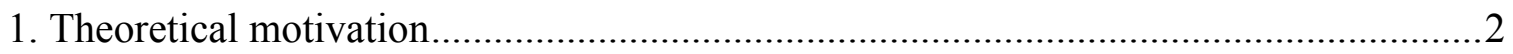

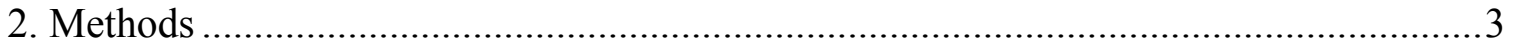

2.1 Data Collection on Amazon Mechanical Turk ……............................................. 3

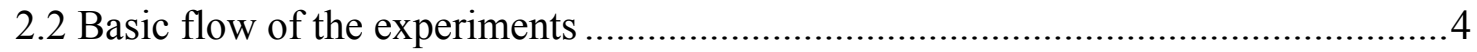

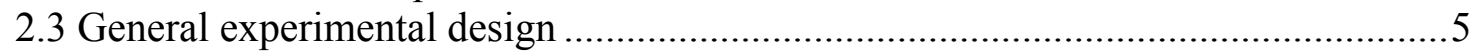

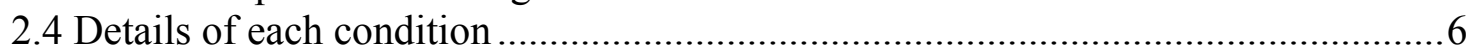

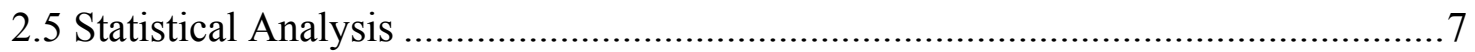

3. Future directions for the IGG and relations to previous work .......................................

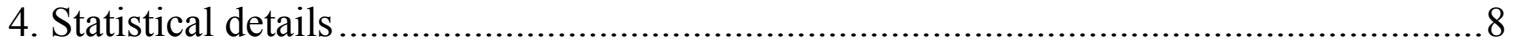

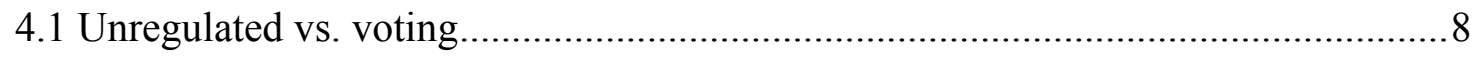

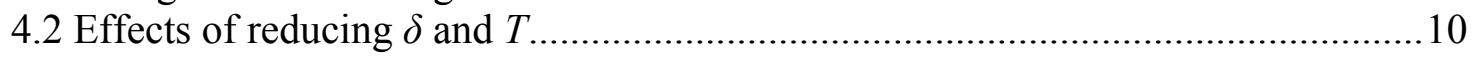

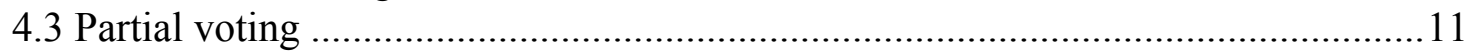

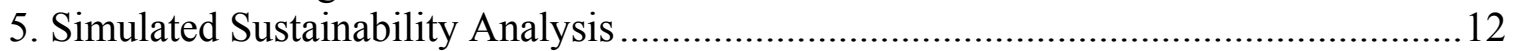

6. Positive association between democracy and sustainability ........................................14

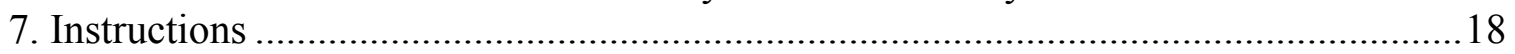

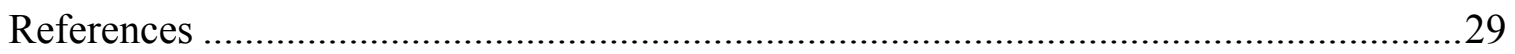




\section{Theoretical motivation}

In this paper, we ask how different institutional rules lead individuals to conserve resources, leaving enough to provide for the next generation. In particular, we are interested in institutions that create sustainable outcomes by harnessing social preferences, and thus may be overlooked when relying on assumptions of rational selfinterest.

We focus on the institution of median voting ${ }^{1-4}$. Among selfish players, median voting can promote intra-generational cooperation (i.e. cooperation in traditional public goods and common pool resource games $)^{3,5}$. The essential structure of intra-generational cooperation is that a group of cooperators earns more than a group of defectors, but that the highest payoff comes from unilaterally defecting in a group where everyone else cooperates. Because median voting binds all players to the same action, unilateral defection is impossible. Therefore the highest payoff is earned by being in a group where everyone cooperates, and selfish players will vote for cooperation. This makes median voting an attractive institution for promoting cooperation under assumptions of rational self-interest in an intra-generational social dilemma.

However, this is not true in the context of intergenerational cooperation. In our intergenerational goods game (IGG), all benefits created by the current generation's cooperation are reaped by subsequent generations. Therefore it is no longer true that a group of cooperators earns more than a group of defectors. Instead, it is the case that a series of cooperative groups, who sustain a pool over multiple generations, earn more in total than a series where one defecting groups exhausts the pool early on. But an individual's payoff is unaffected by the choices of the other members of her own generation. Whereas in the traditional PGG, one's own payoff increases when others in the same group cooperate, in the IGG one's own payoff increases when members of the previous generation have cooperated.

Therefore a player in generation $i$ maximizes her payoff in the IGG by extracting the maximum amount, and is indifferent (monetarily) to the extraction amounts of other members of generation $i$. Because of this, selfish players will vote to extract the maximum amount in the IGG, unlike in the PGG. This would lead traditional theories of public choice, based on rational self-interest, to conclude that median voting is not a good solution for promoting intergenerational transfer.

However, the picture changes dramatically once social preferences are taken into account. A large body of literature suggests that a majority of people in many contexts are not purely self-interested, but instead care to some extent about the well-being of others ${ }^{6}$. People with these kinds of prosocial preferences may be willing to pay a cost to benefit members of future generations. However, they may also have 'conditional cooperation' preferences ${ }^{7}$, which is to say that they prefer cooperating as long as others (both in their own generation and in future generations) cooperate as well. 
Consider how a strong conditional cooperator who cares about future generations would play our IGG (in groups of five). In the unregulated condition, she would cooperate if she expected all four others to cooperate (and all members of future generations to cooperate), and would defect otherwise. Under median voting, however, she would vote for cooperation as long as she expects at least two others in her generation (and 3 others in future generations) to vote for cooperation, because only three cooperative votes are needed to make the median vote cooperative. Thus, in a population of players of which some are future-oriented conditional cooperators, median voting can substantially increase the fraction of people choosing to cooperate.

Furthermore, median voting decreases the number of cooperators needed for sustainability to be achieved. Following similar logic as above, five cooperative choices are needed in the unregulated cases, whereas only three are needed under median voting. Therefore, median voting also makes it easier not to over-exploit the pool.

Critically, however, the predicted success of median voting hinges on a large fraction of the population having social preferences. If all players were purely self-interested, sustainability would never be achieved in either the unregulated or the median voting conditions.

Our experiments are therefore designed to differentiate between the pessimistic prediction of classical public choice theory based on rational self-interest, and the optimistic prediction of a 'behavioural public choice theorem' rooted in social preferences $^{8}$.

\section{Methods}

\subsection{Data Collection on Amazon Mechanical Turk}

For all of our experiments, we recruited U.S. residents to participate using the online labour market Amazon Mechanical Turk (AMT). Our experiment was approved by Harvard University Committee on the Use of Human Subjects in Research, and informed consent was obtained from all subjects.

To preserve random assignment, each generation for all conditions was run at the same time, and subjects within each generation were randomly assigned to one of our seven experimental condition. Each experimental condition is described in more detail below.

AMT is an online market place in which employers can pay users for completing short tasks (generally about 10 minutes) - usually referred to as Human Intelligence Tasks (HITs) - for a relatively small pay (generally less than a \$1). Workers who have been recruited on AMT receive a baseline payment and can also be paid a bonus depending on their performance in the task. This setup lends itself well to adopt incentivised economic experiments: the baseline payment acts as the 'show up' fee and the bonus payment may derive from the workers' behaviour in the economic game and/or other tasks throughout the experiment. 
A major advantage for using AMT is that the sample of recruited subjects has been shown to be more diverse and more nationally representative than the typical college student sample at major research universities, at which many economic games are run ${ }^{9-12}$.

There may, of course, exist potential issues on AMT that would not occur in a traditional laboratory setting. For instance, running an experiment online involves giving up some control over subjects, since they cannot be monitored, as is usually the case in laboratories. That is, it cannot be ruled out that more than a single person is taking part in the experiment or that one person is participating more than once in the experiment (although AMT has put extensive measures into place to avoid this from happening; in addition, we have also implemented ways to carefully screen out any possible re-takers). Finally, the participating subject sample, albeit more diverse and representative than the average college students sample, is biased towards those who participate in online labour markets in the first place. To address these possible concerns, numerous studies have been carried out to validate results collected using AMT. Of particular relevance to the present study, very similar levels of prosociality have been found on AMT and in the lab (using an order of magnitude higher stakes) in a one-shot Prisoner's Dilemma ${ }^{11}$, Public Goods Game $^{10}$, Trust Game ${ }^{10}$ and Ultimatum Game ${ }^{10}$.

\subsection{Basic flow of the experiments}

All participants earned a $\$ 0.50$ showup fee and had the opportunity to earn up to an additional $\$ 1$ in bonus payments depending on the outcome of the IGG. Participants took part in the experiment through an online survey provided by Qualtrics. After participants had read the experiment instructions (see Section 6 below), they had to pass a comprehension quiz about the rules of the game in order to partake in the actual experiment. Those who didn't pass the quiz received only the baseline payment of $\$ 0.50$, and are excluded from our analyses (in accordance with common practice on $\mathrm{AMT}^{11}$ ).

The details of the decision-making stage depended on experimental condition, and the state of the common pool: if the threshold requirement had not been violated by a previous group and the pool had thus refilled to 100 units, participants made their choice about their extraction or vote (depending on the experimental condition they were in; explained in more detailed below). If the extraction threshold had been exceeded previously, the common pool was empty; in this case, the participants were informed about this fact and made no decision nor received any bonus payment beyond the baseline payment (i.e., the show-up fee).

We were concerned that the instructions in the Partial Voting condition were more complicated than in the other conditions, and therefore that substantially more subjects might fail the initial comprehension check in Partial Voting (and thus be excluded). This could be potentially problematic because it would mean that the people who got to participate in the Partial Voting condition would be 'smarter' on average than participants in the other conditions, and this could bias our results if ability to pass more complicated comprehension questions was correlated with behaviour in the IGG. 
We sought to mitigate this problem as follows. After the decision-making stage (so as to not influence their decisions), participants in all conditions other than Partial Voting were presented with the Partial Voting instructions and the corresponding comprehension quiz. Participants had to pass both comprehension checks correctly to receive their bonus, and we only include subjects who passed both quizzes in our analyses. (To keep the experiment approximately equal length across conditions, we also required participants in the Partial Voting condition to read the instructions for the Unregulated condition and answer the associated comprehension questions.)

As expected, substantially fewer subjects passed the first set of comprehension questions in the Partial Voting condition (52\%) compared to the other simpler conditions $(67 \%)$. However, our mitigation strategy was largely successful: the fraction of subjects passing both sets of comprehension questions was much closer, with $49 \%$ passing Partial and $54 \%$ passing in the other conditions. Given the considerable magnitude of our treatment effects reported below, we think it is unlikely that this 5\% difference in comprehension rates had a substantially effect on our results.

The experiments were approved by the Harvard University Committee on the Use of Human Subjects in Research.

\subsection{General experimental design}

In total our experiment had seven experimental conditions: unregulated, baseline voting, voting $\delta=0.7$, voting $\delta=0.6$, voting $\mathrm{T}=40 \%$, voting $\mathrm{T}=30 \%$, partial voting. Before describing the details of each condition, we describe the basic structure which is common to all conditions.

In each condition, 20 resource pools were initiated with 100 units in generation 1 . After every generation, there was a probability $\delta$ that another generation would be recruited (i.e. that the game would be 'continued'). In most conditions, $\delta=0.8$, such that the expected number of generations per game was 5 . We chose a sample size of 20 games per condition at the outset of the experiment, and did not collect any additional data once all 20 games had been run.

Generations were recruited sequentially, with each generation being informed of the outcome of the previous generation as described below. The list of resulting lengths (i.e. \# of generations) for each game in each treatment was:

\begin{tabular}{|l|c|c|c|c|c|c|c|c|c|c|c|c|c|c|c|c|c|c|c|c|}
\hline Unregulated & 8 & 2 & 6 & 3 & 4 & 12 & 2 & 2 & 13 & 3 & 6 & 1 & 5 & 4 & 6 & 1 & 5 & 4 & 5 & 4 \\
\hline Voting baseline & 5 & 2 & 1 & 8 & 5 & 5 & 3 & 5 & 2 & 1 & 12 & 1 & 4 & 5 & 2 & 3 & 1 & 2 & 5 & 2 \\
\hline Voting $\delta=0.7$ & 4 & 1 & 1 & 2 & 5 & 1 & 3 & 2 & 6 & 2 & 2 & 2 & 5 & 3 & 13 & 2 & 9 & 1 & 1 & 6 \\
\hline Voting $\delta=0.6$ & 6 & 1 & 2 & 1 & 1 & 2 & 5 & 8 & 1 & 2 & 2 & 1 & 1 & 2 & 8 & 6 & 3 & 4 & 4 & 1 \\
\hline Voting $T=40 \%$ & 4 & 1 & 12 & 4 & 1 & 12 & 4 & 2 & 6 & 14 & 13 & 5 & 1 & 7 & 12 & 4 & 1 & 5 & 7 & 5 \\
\hline Voting $T=30 \%$ & 5 & 4 & 1 & 6 & 6 & 6 & 3 & 5 & 6 & 4 & 1 & 1 & 3 & 5 & 6 & 13 & 4 & 10 & 2 & 1 \\
\hline Partial Voting & 13 & 1 & 1 & 3 & 2 & 14 & 5 & 1 & 11 & 2 & 3 & 5 & 9 & 1 & 5 & 7 & 1 & 4 & 9 & 2 \\
\hline
\end{tabular}


Within each generation of a game, a group of five participants chose how many units to extract from the pool (out of a total of 100 units). (The mechanism by which this choice was made varied across conditions, as described below). If the fraction extracted within a given group did not exceed the extraction threshold of $T$, that group's pool would be 'sustained': the next generation would receive a pool refilled to 100 units and have a chance to make their own set of extraction decisions (provided that the game was continued based on the continuation probability $\delta$ such that there was indeed another generation).

If, on the other hand, the fraction extracted exceeded $T$, the pool was exhausted. All future generations were informed that previous more than $T$ units had been extracted from the pool, and as a result they (the current generation) would not have the opportunity to play the IGG or receive any bonus payment.

Participants in Generation 1 were informed that they were the first generation. Participants in subsequent generations were informed that the previous generation had either sustained or not sustained the pool. They were not informed, however, of the specific generation number (other than showing that they were not the first) they were because the total number of continued generations varied across pools and conditions due to the random continuation device, and we did not want to introduce this as a source of bias.

Note that in the IGG, a series of generations where each generation acts sustainably (i.e., extracts $T$ units) has an expected total payoff of $T /(1-\delta)$. A series of generations where everyone extracts the maximum (and therefore the pool is exhausted after the first generation), has an expected total payoff of 100 (the contents of the pool in the first generation). Thus acting sustainably is socially efficient as long as $T /(1-\delta)>100$.

\subsection{Details of each condition}

Our experimental conditions differed in two ways: the manner in which the number of extracted units was determined (i.e., the institution: unregulated, voting, or partial voting) and the specific values of $\delta$ and $T$.

First we describe the three different institutions.

- Under the unregulated institution, each of the five group members independently selected an extraction amount between 0 and 20 units.

- Under the voting institution, each of the five group members proposed an extraction amount between 0 and 20 units. The median proposal amount was then extracted for each group member.

- Under the partial voting institution, (i) three of the five group members proposed an extraction amount between 0 and 20 units and the median proposal amount was then extracted for each of the three; while (ii) the other two group members independently selected an extraction amount between 0 and 20 units. 
The values of $\delta$ and $T$ used in condition are given below, as well as the average game length and resulting number of subjects recruited (note that the criterion for sustainability to be socially efficient, $T /(1-\delta)>100$, is met in all cases):

\begin{tabular}{|l|c|c|c|c|}
\hline Condition & $\boldsymbol{\delta}$ & $\boldsymbol{T}$ & Mean \# Generations & $\boldsymbol{N}$ \\
\hline Unregulated & 0.8 & $50 \%$ & 4.8 & 480 \\
\hline Voting & 0.8 & $50 \%$ & 3.7 & 370 \\
\hline Voting $\delta=0.7$ & 0.7 & $50 \%$ & 3.6 & 355 \\
\hline Voting $\delta=0.6$ & 0.6 & $50 \%$ & 3.1 & 305 \\
\hline Voting $T=40 \%$ & 0.8 & $40 \%$ & 6.0 & 600 \\
\hline Voting $T=30 \%$ & 0.8 & $30 \%$ & 4.6 & 460 \\
\hline Partial voting & 0.8 & $50 \%$ & 5.0 & 495 \\
\hline
\end{tabular}

\subsection{Statistical Analysis}

To analysis the data, we use linear probability models to estimate the effect of institution on pool sustainability. Groups in which the game was continued and the pool was sustained are coded as 1 (i.e., groups which received a full pool and did not extract more than $T$ units). Groups in which the game was continued but the pool was exhausted are coded as 0 (i.e., groups which received a full pool and extracted more than $T$ units, or groups which received an exhausted pool). Once a game was discontinued (i.e., after the random number drawn for continuation was greater than $\delta$ ), no more groups were recruited and so no subsequent generations for that pool appear in the regression.

Thus we compare the fraction of continued games that have sustained pools, with one observation per group of five participants. Because of the randomness of the continuation device, the number of groups is not identical across conditions. To partially address this issue, as well as to account for the fact that outcomes of groups which receive exhausted pools are not independent of outcomes of earlier groups in that game, we cluster standard errors in our regressions at the level of the game. Furthermore, in Section 4, we compliment this regression analysis with an analysis using a large number of simulated game lengths and random permutations of extraction decisions/proposals.

\section{Future directions for the IGG and relations to previous work}

In the game theoretic tradition, the IGG framework is a great simplification relative to real-world intergenerational cooperation. We feel that this simplification captures key elements of the intergenerational challenge facing our world: the game is non-zero sum, with cooperation today creating greater benefits for the future; the consequences of consumption are non-linear, such that some amount of consumption can occur in the present without imposing costs on the future; and the cooperative challenge involves group-level decisions rather than just individual-to-individual transfers. 
There are, however, many aspects of intergenerational cooperation which the IGG does yet not incorporate. Although we include a probabilistic continuation rule for future discounting, there may be important elements of the psychology of discounting which this approach does not capture. Additionally, future generations are our relatives, will likely be richer than us, and may have access to technological innovations that could mitigate our current environmental concerns.

Future work extending our IGG framework to examine these issues, as well as exploring intergenerational cooperation among larger groups, overlapping generations ${ }^{13}$, and groups with the possibility of borrowing against the future (i.e. running up national debt) will help to advance our understanding of real-world intergenerational cooperation. So too will considering spatial effects, where over-consumption in one area has little consequence for individuals living far away ${ }^{14}$.

Our IGG experiments add to a nascent literature on cooperation across generations. Previous work has demonstrated that coordination, communication and social reputation help meet targets in groups to avoid collective loss ${ }^{15-18}$. Our voting intervention is also a type of coordination mechanism. It helps coordinate people's preferences towards their own gains and those of future generations ${ }^{19}$.

Additionally, other work has emphasised that altruism depends on previous generations' behaviour as well as the personal distance between donors and recipients of the intergenerational good ${ }^{20,21}$. We thus expect that the results in our IGG would be further magnified if the longevity of a common pool was made salient to later generations or if personal relationships existed between individual members of generations, as in the case of families. In contrast, we expect that factors such as uncertainty, inequality, and global sanctioning approaches would lead to lower rates of cooperation and sustainability ${ }^{17,22,23}$.

Our experiments also build on previous work exploring the interaction between voting institutions and social preferences. In particular, it has been shown that voting mechanisms can override anti-social behaviour where cooperators are punished, because typically only a minority hold such anti-social preferences ${ }^{4,8,24}$. Our results extend this 'behavioural public choice theorem'. We demonstrate how voting can allow a majority of prosocial individuals to override a purely selfish (rather than anti-social) minority, leading to costly group-level cooperation with future generations.

\section{Statistical details}

\subsection{Unregulated vs. voting}

Here we ask the basic question of how sustainability under the unregulated institution compares to sustainability under the voting institution (both using $\delta=0.8$ and $T=50 \%$ ). We begin by considering just the first generation (Table S1 col. 1). We see that dramatically more pools are sustained under voting. Pooling across all generations (Table S1 col. 2) we see an even bigger positive effect of voting. 
Table S1: Linear probability model estimating the effect of institution on pool sustainability. Standard errors clustered at pool level.

\begin{tabular}{lcc}
\hline & 1st Generation & All Generations \\
\hline $1=$ Voting & 0.800 & 0.938 \\
& $(0.092)^{* * *}$ & $(0.025)^{* * *}$ \\
Constant & 0.200 & 0.062 \\
& $(0.092)^{*}$ & $(0.025)^{*}$ \\
$R^{2}$ & 0.67 & 0.87 \\
$N$ & 40 & 170 \\
\hline \multicolumn{3}{c}{}
\end{tabular}

In addition to this group-level outcome, we examine how the voting institution changes behaviour at the individual level. In particular, we examine the fraction of subjects behaving prosocially in each condition.

To do so, we label individuals as "cooperators" if they choose to extract 10 units or less in the unregulated condition, or vote to extract 10 units or less in the voting condition. We then use a linear probability model to estimate the effect of institution on proportion of cooperators. Both in the first generation (Table S2 col. 1) and over all generations (Table S2 col. 2), significantly more participants are cooperators in the voting condition than the unregulated treatment.

To demonstrate that this finding is not an artefact of our binary classification of subjects as Cooperators or Non-cooperators, we also estimate the effect of institution on participants' decision (extraction amount in unregulated, proposal amount in voting). Consistent with the binary analysis, participants' decision extraction amounts are significantly lower under voting than when unregulated, both in the first generation (Table S2 col. 3) and over all generations (Table S2 col. 4).

Table S2: Linear probability model estimating the effect of institution on likelihood of cooperation (col 1 and 2). Linear regression estimating the effect of institution on average decision (col 3 and 4). Standard errors clustered at the pool level.

\begin{tabular}{|c|c|c|c|c|}
\hline & \multicolumn{2}{|c|}{ Cooperator? } & \multicolumn{2}{|c|}{ Decision/Proposal } \\
\hline & $1^{\text {st }}$ Generation & All Generations & $1^{\text {st }}$ Generation & All Generations \\
\hline $1=$ Voting & $\begin{array}{l}0.220 \\
(0.062)^{* * *}\end{array}$ & $\begin{array}{l}0.201 \\
(0.050)^{* * *}\end{array}$ & $\begin{array}{l}-1.980 \\
(0.784)^{*}\end{array}$ & $\begin{array}{l}-2.290 \\
(0.634)^{* * *}\end{array}$ \\
\hline Constant & $\begin{array}{l}0.660 \\
(0.054)^{* * *}\end{array}$ & $\begin{array}{l}0.677 \\
(0.048)^{* * *}\end{array}$ & $\begin{array}{l}11.480 \\
(0.677)^{* * *}\end{array}$ & $\begin{array}{l}11.485 \\
(0.589)^{* * *}\end{array}$ \\
\hline$R^{2}$ & 0.07 & 0.05 & 0.03 & 0.04 \\
\hline$N$ & 200 & 500 & 200 & 500 \\
\hline
\end{tabular}




\subsection{Effects of reducing $\delta$ and $T$}

Next we ask how reducing the discount factor $\delta$ and the extraction threshold $T$ affects sustainability in the voting institution. To do so, we analyse all data from the five voting conditions (but not the 'partial voting' condition) jointly in a linear probability model, and estimate the probability of pools being sustained.

Examining just the first generation (Table S3 col. 1), we see that neither $\delta(p=0.223)$ nor $T(p=0.441)$ significantly affect sustainability, although both effects are trending in the positive direction (i.e. lower $\delta$ and lower $T$ lead to less sustainability). Examining all generations (Table S3 col. 2), these effects accumulate, and we do observe significant decreases in sustainability when decreasing either $\delta(p=0.037)$ or $T(p<0.001)$. However, the size of these effects is not so large quantitatively: decreasing $\delta$ by 0.1 decreases the probability of a pool being sustained by $4.6 \%$; and decreasing $T$ by $10 \%$ decreases the probability of a pool being sustained by $14.6 \%$.

Table S3: Linear probability model estimating the effect of $\delta$ and $T$ on pool sustainability under the voting institution. Standard errors clustered at pool level.

\begin{tabular}{lcc}
\hline & $1^{\text {st }}$ Generation & All Generations \\
\hline$\delta$ & 0.300 & 0.460 \\
& $(0.245)$ & $(0.220)^{*}$ \\
& 0.002 & 0.015 \\
Constant & $(0.003)$ & $(0.002)^{* * *}$ \\
& 0.660 & -0.119 \\
$R^{2}$ & $(0.254)^{*}$ & $(0.235)$ \\
$N$ & 0.01 & 0.08 \\
\multicolumn{3}{c}{} \\
& 100 & 418 \\
\hline
\end{tabular}

Most importantly, the probability of a pool being sustained under voting in any of these reduced $\delta$ or $T$ cases is dramatically higher than when unregulated (Fraction of pools sustained: Unregulated, $6.3 \% ; \delta=0.7,94 \% ; \delta=0.6,89 \%, T=40,81 \% ; T=30,71 \%$; all differences from unregulated $p<0.001$, see Table S4). Note that this is true even though the unregulated condition has the advantage of higher $\delta$ or $T$, depending on the voting condition. 
Table S4: Linear probability model comparing pool sustainability in the unregulated condition (taken as the baseline) to the voting institutions with reduced $\delta$ or $T$. Standard errors clustered at pool level.

\begin{tabular}{|c|c|c|}
\hline & $1^{\text {st }}$ Generation & All Generations \\
\hline $1=$ Voting $\delta=0.7$ & $\begin{array}{l}0.750 \\
(0.105)^{* * *}\end{array}$ & $\begin{array}{l}0.881 \\
(0.037)^{* * *}\end{array}$ \\
\hline $1=$ Voting $\delta=0.6$ & $\begin{array}{l}0.750 \\
(0.105)^{* * *}\end{array}$ & $\begin{array}{l}0.823 \\
(0.048)^{* * *}\end{array}$ \\
\hline $1=$ Voting $T=40 \%$ & $\begin{array}{l}0.750 \\
(0.105)^{* * *}\end{array}$ & $\begin{array}{l}0.644 \\
(0.054)^{* * *}\end{array}$ \\
\hline $1=$ Voting $T=30 \%$ & $\begin{array}{l}0.800 \\
(0.092)^{* * *}\end{array}$ & $\begin{array}{l}0.746 \\
(0.044)^{* * *}\end{array}$ \\
\hline Constant & $\begin{array}{c}0.200 \\
(0.092)^{*}\end{array}$ & $\begin{array}{c}0.062 \\
(0.025)^{*}\end{array}$ \\
\hline$R^{2}$ & 0.61 & 0.46 \\
\hline$N$ & 100 & 440 \\
\hline
\end{tabular}

\subsection{Partial voting}

Finally, we examine the effect of a partial voting institution, under which only three of the five group members are bound by a vote. We use $\delta=0.8$ and $T=50 \%$, and compare the fraction of pools sustained to all of our previous conditions. To do so, we use a linear probability model taking partial voting as the baseline, and estimate the proportion of pools sustained including dummies for each other condition.

We see that both in the first generation (Table S5 col. 1) and over all generations (Table S5 col. 2), sustainability is dramatically lower in the partial voting condition than in any of the voting conditions, although partial voting does still lead to somewhat more sustainability than the unregulated case. 
Table S5: Linear probability model comparing pool sustainability in the partial voting condition (taken as the baseline) to all other conditions. Standard errors clustered at pool level.

\begin{tabular}{|c|c|c|}
\hline & $1^{\text {st }}$ Generation & All Generations \\
\hline $1=$ Unregulated & $\begin{array}{l}-0.500 \\
(0.140)^{* * *}\end{array}$ & $\begin{array}{l}-0.261 \\
(0.053)^{* * *}\end{array}$ \\
\hline $1=$ Voting baseline & $\begin{array}{l}0.300 \\
(0.105)^{* *}\end{array}$ & $\begin{array}{l}0.677 \\
(0.047)^{* * *}\end{array}$ \\
\hline $1=$ Voting $\delta=0.7$ & $\begin{array}{l}0.300 \\
(0.105)^{* *}\end{array}$ & $\begin{array}{l}0.485 \\
(0.060)^{* * *}\end{array}$ \\
\hline $1=$ Voting $\delta=0.6$ & $\begin{array}{c}0.250 \\
(0.116)^{*}\end{array}$ & $\begin{array}{l}0.383 \\
(0.067)^{* * *}\end{array}$ \\
\hline $1=$ Voting $\mathrm{T}=40 \%$ & $\begin{array}{c}0.250 \\
(0.116)^{*}\end{array}$ & $\begin{array}{l}0.620 \\
(0.055)^{* * *}\end{array}$ \\
\hline $1=$ Voting $\mathrm{T}=30 \%$ & $\begin{array}{c}0.250 \\
(0.116)^{*}\end{array}$ & $\begin{array}{l}0.562 \\
(0.063)^{* * *}\end{array}$ \\
\hline Constant & $\begin{array}{l}0.700 \\
(0.105)^{* * *}\end{array}$ & $\begin{array}{l}0.323 \\
(0.047)^{* * *}\end{array}$ \\
\hline$R^{2}$ & 0.50 & 0.47 \\
\hline$N$ & 140 & 613 \\
\hline
\end{tabular}

\section{Simulated Sustainability Analysis}

Our analyses thus far have examined the actual outcomes that occurred in our experiment: the fraction of available pools that had been sustained in each generation, across the 20 pools initialized at the start of each condition. There are numerous sources of stochasticity that introduce noise into these comparisons. Due to the random continuation probability, some conditions lasted for more generations on average than others. The particular random matching of subjects into groups of five can affect the outcome: consider five subjects that cooperate and extract 10 units in the baseline, and five other subjects that defect and extract 20 units. A random matching that puts the five cooperators together and the five defectors together results in one sustained pool and one exhausted pool. But any other matching would result in two exhausted pools. Finally, a pool which is exhausted in an early generation which is then continued for many generations results in a very low sustainability score; whereas if the same pool had been continued for only one round, it would have had a high sustainability score.

We address all of these sources of noise by conducting a set of computer simulations using the data generated by our participants. To do so, we take advantage of the fact that after the first generation, all subjects in a given condition received the same set of information, and therefore made decisions which are effectively interchangeable. Thus in each simulation run, we randomly sample (with replacement) a series of generations of 
participant decisions, and calculate the fraction of those generations in which the pool was refilled.

Specifically, our procedure worked as follows, for each condition:

1. For the first generation, randomly sample (with replacement) five participants from the first generation of the current experimental condition.

2. Based on their decisions, and the rules of the experimental condition, determine whether the pool is sustained or exhausted.

3. Determine if this game is continued for another generation by comparing a random number to $\delta$.

4. If so, randomly sample (with replacement) five participants from all generations of the current experimental condition except the first generation.

5. If the pool has previously been exhausted, mark this generation as non-sustained. If the pool has not previously been exhausted, mark this generation as sustained, and determine (based on the sampled decisions and the rules of the experimental condition) whether the pool is sustained or exhausted for the next generation.

6. Determine if this game is continued for another generation by comparing a random number to $\delta$. If so, repeated steps 4 thru 6 .

Using this procedure, we first simulated 10,000 pools out to 15 generations for the Unregulated, Voting and Partial Voting conditions. As can be seen in Extended Data Figure 1a, the results are striking: the Voting institution is dramatically more successful at sustaining the pool than either the Partial Voting or the Unregulated conditions.

We also used this procedure to examine the consequences of changing $\delta$ and $T$ under the Voting institution. To do so, we simulated 10,000 games out to 15 generations for the $T=$ $40 \%$ and $T=30 \%$ conditions, and 1,000,000 games out to 15 generations for the $\delta=0.7$ and $\delta=0.6$ conditions, and compared the results to the Voting condition simulations above. We simulated a larger number of replicates for the lower $\delta$ conditions because the games in those conditions were dramatically shorter on average, and so many more replicated were required to get a reasonable amount of data out to 15 generations. As can be seen in Extended Data Figure 1b, reducing $\delta$ has only a small effect, and although reducing $T$ does undermine sustainability, the effect is much less dramatic than that of Unregulated or Partial Voting despite the higher value of $T$ in these less-regulated conditions. 


\section{Positive association between democracy and sustainability}

Our experiments suggest that a democratic institution can help a majority of prosocial individuals override a purely selfish minority, leading to costly group-level cooperation with future generations. Real-world data are consistent with this suggestion from our experiments: across 128 countries, more democratic institutions are associated with greater efforts to act sustainably and mitigate environmental impact.

To provide this evidence, we combine data from two independent sources: The 2012 Democracy Index ${ }^{25}$ created by the Economist Intelligence Unit (EIU, part of the Economist magazine family of businesses) and the 2013 Sustainability Index created by the organization World Energy ${ }^{26}$. Both data files are publicly accessible on the respective websites. We examine the 128 countries included in both datasets.

The Democracy Index (DI) is calculated using a weighted average of a 60-item measure with items distributed over five categories: electoral process, civil liberties, government, political participation, and political culture. In addition to assigning a numeric DI to each of 167 countries, the EIU also classifies each country into one of our regime types by its index. The four regime types are (DI ranges in parentheses): Full Democracies (DI $\geq 8$ ), Flawed Democracies $(6 \leq \mathrm{DI}<8)$, Hybrid Regimes $(4 \leq \mathrm{DI}<6)$, and Authoritarian Regimes (DI < 4).

The Energy Sustainability Index is a composite of three subscales:

- Energy security - the effective management of primary energy supply from domestic and external sources, the reliability of energy infrastructure, and the ability of participating energy companies to meet current and future demand.

- Energy equity - the accessibility and affordability of energy supply across the population.

- Environmental sustainability - the achievement of supply and demand-side energy efficiencies and the development of energy supply from renewable and other lowcarbon sources.

We analyse both the overall sustainability index as well as the environmental impact mitigation subscale since it is the most directly relevant to our question of interest.

Consistent with our experimental results, we find that there is a significant positive correlation between democratic institutions and sustainability (Extended Data Figure 2): countries with higher democracy scores also score higher in their efforts to act sustainably (Table $\mathrm{S} 6 \mathrm{Col} 1 ; p<0.001$ ) and specifically to mitigate environmental impact (Table S7 Col 1; $p<0.001$ ).

As a first step towards testing the robustness of this relationship, we examine the effect of including controls for the 2014 gross domestic product ${ }^{27}$ (GDP, in US\$, compiled by the World Bank), Gini index ${ }^{28}$ (a measure of wealth inequality, using the most recent year available for each country on quandl.com), literacy rates $^{29}$ (using the most recent year available for each country, complied by the Central Intelligence Agency), average life expectancy ${ }^{30}$ in each country in 2013 (complied by the World Health Organization), the 
level of corruption ${ }^{31}$ in each country (compiled in 2004 by the World Bank), each country's population $\operatorname{size}^{28}$ and the rate of unemployment ${ }^{28}$ (both using the most recent year available for each country on quandl.com). Missing values for controls are interpolated, using the mean of all non-missing values. As shown in Tables S6 Col 2 and S7 Col 2, we continue to find a significant positive relationship between democracy scores and both the overall sustainability index $(p=0.001)$ and the environmental impact mitigation score $(p<0.001)$. Finally, we also consider the effects of the logarithmic transformations of GDP and population size of each country, as these variables are heavily right-skewed. We find that our results remain unchanged (Col 3 in Tables S6 and S7): more democratic institutions have more sustainable energy policies $(p<0.001)$ and engage in greater efforts to mitigate environmental impact $(p<0.001)$.

Thus we provide preliminary evidence that democracy may indeed lead to better environmental practices. Obviously this analysis does not control many additional potential confounding factors, and is correlational, not causal. We hope that these preliminary results will inspire empirical scholars to investigate this issue further in future work. 
Table S6. Linear regression predicting the overall sustainability index with democracy score.

\begin{tabular}{|c|c|c|c|}
\hline & $\begin{array}{l}\text { Sustainability } \\
\text { Index }\end{array}$ & $\begin{array}{l}\text { Sustainability } \\
\text { Index }\end{array}$ & $\begin{array}{l}\text { Sustainability } \\
\text { Index }\end{array}$ \\
\hline Democracy index & $\begin{array}{l}0.585 \\
(0.073)^{* * *}\end{array}$ & $\begin{array}{l}0.211 \\
(0.062)^{* * *}\end{array}$ & $\begin{array}{l}0.227 \\
(0.054)^{* * *}\end{array}$ \\
\hline GDP (in US\$) & & $\begin{array}{c}1.710 \mathrm{e}-07 \\
(7.143 \mathrm{e}-08)^{*}\end{array}$ & \\
\hline Gini index & & $\begin{array}{l}-0.008 \\
(0.013)\end{array}$ & $\begin{array}{l}-0.004 \\
(0.012)\end{array}$ \\
\hline Population size & & $\begin{array}{l}-1.376 \mathrm{e}-06 \\
(4.761 \mathrm{e}-07)^{* *}\end{array}$ & \\
\hline Literacy rate & & $\begin{array}{l}2.753 \\
(1.096)^{*}\end{array}$ & $\begin{array}{c}1.003 \\
(0.963)\end{array}$ \\
\hline Unemployment rate & & $\begin{array}{l}-2.651 \\
(1.982)\end{array}$ & $\begin{array}{l}-1.298 \\
(1.703)\end{array}$ \\
\hline Life expectancy (years) & & $\begin{array}{c}0.060 \\
(0.028)^{*}\end{array}$ & $\begin{array}{c}0.006 \\
(0.022)\end{array}$ \\
\hline Level of corruption & & $\begin{array}{l}0.022 \\
(0.006)^{* * *}\end{array}$ & $\begin{array}{c}0.011 \\
(0.006)\end{array}$ \\
\hline $\log (\mathrm{GDP})$ & & & $\begin{array}{l}0.782 \\
(0.170) * * *\end{array}$ \\
\hline $\log$ (Population) & & & $\begin{array}{l}-0.591 \\
(0.181)^{* *}\end{array}$ \\
\hline Constant & $\begin{array}{l}1.454 \\
(0.474)^{* *}\end{array}$ & $\begin{array}{l}-3.703 \\
(1.807)^{*}\end{array}$ & $\begin{array}{l}-1.424 \\
(1.763)\end{array}$ \\
\hline$R^{2}$ & 0.36 & 0.63 & 0.72 \\
\hline$N$ & 128 & 128 & 128 \\
\hline
\end{tabular}

$* p<0.05 ; * * p<0.01 ; * * * p<0.001$ 
Table S7. Linear regression predicting the environmental impact mitigation score with democracy score.

\begin{tabular}{|c|c|c|c|}
\hline & $\begin{array}{c}\text { Environmental } \\
\text { Impact Mitigation } \\
\text { Score }\end{array}$ & $\begin{array}{c}\text { Environmental } \\
\text { Impact Mitigation } \\
\text { Score }\end{array}$ & $\begin{array}{c}\text { Environmental } \\
\text { Impact Mitigation } \\
\text { Score }\end{array}$ \\
\hline Democracy index & $\begin{array}{l}0.652 \\
(0.107) * * *\end{array}$ & $\begin{array}{l}0.662 \\
(0.130) * * *\end{array}$ & $\begin{array}{l}0.668 \\
(0.130) * * *\end{array}$ \\
\hline GDP (in US\$) & & $\begin{array}{c}1.274 \mathrm{e}-08 \\
(1.373 \mathrm{e}-07)\end{array}$ & \\
\hline Gini index & & $\begin{array}{c}0.040 \\
(0.031)\end{array}$ & $\begin{array}{c}0.039 \\
(0.031)\end{array}$ \\
\hline Population size & & $\begin{array}{l}-3.523 \mathrm{e}-06 \\
(1.128 \mathrm{e}-06) * *\end{array}$ & \\
\hline Literacy rate & & $\begin{array}{l}-2.089 \\
(2.077)\end{array}$ & $\begin{array}{l}-2.022 \\
(2.295)\end{array}$ \\
\hline Unemployment rate & & $\begin{array}{l}-1.598 \\
(4.408)\end{array}$ & $\begin{array}{l}-1.524 \\
(4.667)\end{array}$ \\
\hline $\begin{array}{l}\text { Life expectancy } \\
\text { (years) }\end{array}$ & & $\begin{array}{l}0.030 \\
(0.049)\end{array}$ & $\begin{array}{r}0.038 \\
(0.056)\end{array}$ \\
\hline Level of corruption & & $\begin{array}{c}0.002 \\
(0.013)\end{array}$ & $\begin{array}{c}0.005 \\
(0.015)\end{array}$ \\
\hline $\log (\mathrm{GDP})$ & & & $\begin{array}{l}-0.118 \\
(0.332)\end{array}$ \\
\hline $\log$ (Population) & & & $\begin{array}{l}-0.088 \\
(0.351)\end{array}$ \\
\hline Constant & $\begin{array}{c}1.029 \\
(0.676)\end{array}$ & $\begin{array}{l}-0.796 \\
(3.026)\end{array}$ & $\begin{array}{c}0.443 \\
(4.371)\end{array}$ \\
\hline$R^{2}$ & 0.21 & 0.26 & 0.24 \\
\hline$N$ & 128 & 128 & 128 \\
\hline
\end{tabular}




\section{Instructions}

\section{Sample Instructions for Main Conditions}

Unregulated treatment (all instructions and comprehension questions on the same page):

This HIT involves a sequence of groups. There is a common pool that is passed from one group to the next. This pool can be harvested to generate bonuses. If the pool is overexploited, it will be destroyed and subsequent groups cannot earn any bonuses.

Each group is made up of five people. You are in one of those groups.

You and the four other people in your group will each make a decision. Your decision determines the money you earn, and it can affect the potential earnings of all subsequent groups.

The common pool contains 100 units.

Each person in your group decides how many units to take out of the pool.

Each person can take out between 0 and 20 units.

For each unit you take out, you get a bonus of 5 cents.

If your group takes out a total of $\mathbf{5 0}$ units or less, the pool is refilled to 100 units.

If your group takes out a total of more than $\mathbf{5 0}$ units, the pool is permanently destroyed (set to 0 units). In this case none of the future groups can earn any bonus.

After your group has finished, there is an $80 \%$ chance that the common pool (refilled or destroyed) will be passed on to another group. There is a $20 \%$ chance that the study ends.

Here is a summary of the game:

In the beginning the common pool contains 100 units.

It is first given to Group 1. They make their decisions.

If Group 1 extracts 50 units or less, the pool refills to 100 units. Otherwise it goes to 0 units.

After Group 1, there is an $80 \%$ probability that there will be another group playing (Group 2). Group 2 can only earn a bonus if Group 1 passes on a pool that has refilled to 100 units. If Group 2 extracts 50 units or less, the pool refills to 100 units. Otherwise it goes to 0 units.

After Group 2, there is an $80 \%$ probability that there will be another group playing (Group 3). Group 3 can only earn a bonus if Group 2 passes on a pool that has refilled to 100 units. If Group 3 extracts 50 units or less, the pool refills to 100 units. Otherwise it goes to 0 units.

\section{And so on:}

After each group, there is an $80 \%$ probability that there will be another group. The next group can only earn a bonus, if the group before them did not extract more than 50 units.If a group extracts more than 50 units, then no subsequent group can earn a bonus. 
Here are two examples:

Example 1:

The five players in Group 1 extract the following units: $9,10,7,16,8$. Together the players extracted $9+10+7+16+8=50$ units which counts as $\mathbf{5 0}$ units or less. The common pool will refill back to 100 units. There is an $80 \%$ probability that there will be a Group 2 . If so, they receive a pool with 100 units. In that case, Group 2 can earn a bonus.

\section{Example 2:}

The five players in Group 3 extract the following units: 19, 14, 8, 3, 7. Together the players extracted $19+14+8+3+7=51$ units which counts as more than $\mathbf{5 0}$ units. The common pool will not refill to 100 units. There is an $80 \%$ probability that there will be a Group 4 . If so, they receive a pool with 0 units. In that case, Groups 4 (and all future groups) cannot earn a bonus.

To make sure you understood the game, please answer the comprehension questions below.

YOU MUST ANSWER THESE QUESTIONS CORRECTLY TO BE ELIGIBLE TO RECEIVE YOUR BONUS FOR THIS HIT.

If one player extracts 9 units, one player extracts 8 units, one player extracts 17 units, one player extracts 12 units, and one player extracts 10 units, will the common pool pass on to the next group?

Yes, the common pool will refill (100 units).

No, the common pool not refill - it will be emptied to 0 units.

How likely is it that there will be another group?
$60 \%$
○ $80 \%$
○ $100 \%$

If your group extracted more than $\mathbf{5 0}$ units, can future groups earn a bonus?
Yes
No

Correct answers: 1) No (because $8+9+10+12+17$ units $>50$ ), 2) $80 \%, 3$ ) No. 
For those subjects who pass the quiz, the next page is always the decision-making screen. Within a treatment, this screen is identical for every generation except for the first generation. Between treatments, the only change is the treatment-specific wording (e.g., in Unregulated, "How many units do you want to extract from the common pool?" is replaced by "How many units do you propose should be extracted by each player?" in the Voting treatment).

Here is the decision-making screen for the first generation in Unregulated:

\section{You are in Group 1.}

How many units do you want to extract from the common pool?

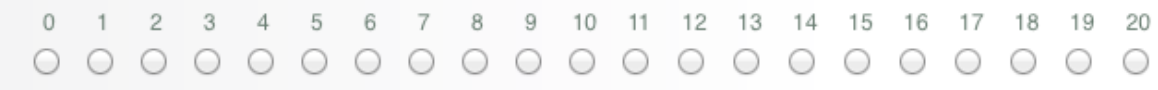

For every generation afterwards, the screen looks as follows:

The previous group extracted $\mathbf{5 0}$ units or less from the common pool. Thus, the pool refilled to 100 units.

You have the chance to earn a bonus.

How many units do you want to extract from the common pool?

Those (in later generations) that received an empty pool saw the following message:

The previous group extracted more than $\mathbf{5 0}$ units from the common pool.

You cannot earn a bonus from the common pool. The game is over.

Please make sure to finish this short survey to receive $\$ 0.50$ for this HIT. 
Instructions in the Voting treatment:

This HIT involves a sequence of groups. There is a common pool that is passed from one group to the next. This pool can be harvested to generate bonuses. If the pool is overexploited, it will be destroyed and subsequent groups cannot earn any bonuses.

Each group is made up of five people. You are in one of those groups.

You and the four other people in your group will each make a decision. Your decision determines the money you earn, and it can affect the potential earnings of all subsequent groups.

The common pool contains 100 units.

Each person in your group will take the same number of units out of the pool.

Each person proposes an amount to take out, between 0 and 20 units.

The five proposals are sorted from smallest to largest value.

The value in the middle is then selected: each of you extracts that amount.

For each unit you extract, you get a bonus of 5 cents.

If your group takes out a total of $\mathbf{5 0}$ units or less, the pool is refilled to 100 units.

If your group takes out a total of more than $\mathbf{5 0}$ units, the pool is permanently destroyed (set to 0 units). In this case none of the future groups can earn any bonus.

After your group has finished, there is an $80 \%$ chance that the common pool (refilled or destroyed) will be passed on to another group. There is a $20 \%$ chance that the study ends.

\section{Here is a summary of the game:}

In the beginning the common pool contains 100 units.

It is first given to Group 1. They make their decisions.

If Group 1 extracts 50 units or less, the pool refills to 100 units. Otherwise it goes to 0 units.

After Group 1, there is an $80 \%$ probability that there will be another group playing (Group 2). Group 2 can only earn a bonus if Group 1 passes on a pool that has refilled to 100 units. If Group 2 extracts 50 units or less, the pool refills to 100 units. Otherwise it goes to 0 units.

After Group 2, there is an $80 \%$ probability that there will be another group playing (Group 3). Group 3 can only earn a bonus if Group 2 passes on a pool that has refilled to 100 units. If Group 3 extracts 50 units or less, the pool refills to 100 units. Otherwise it goes to 0 units.

And so on:

After each group, there is an $80 \%$ probability that there will be another group. The next group can only earn a bonus, if the group before them did not extract more than 50 units. If a group extracts more than 50 units, then no subsequent group can earn a bonus. 
Here are two examples:

Example 1:

The five players in Group 1 propose to take out the following units: $9,10,7,16,10$. The values are sorted from smallest to largest $(7,9,10,10,16)$ and the middle value is selected: 10 . Together the players extracted $5 * 10=50$ units which counts as $\mathbf{5 0}$ units or less. The common pool will refill back to 100 units. There is an $80 \%$ probability that there will be a Group 2 . If so, they receive a pool with 100 units. In that case, Group 2 can earn a bonus.

Example 2:

The five players in Group 3 propose to take out the following units: 19, 20, 8, 3, 11. The values are sorted from smallest to largest $(3,8,11,19,20)$ and the middle value is selected: 11 . Together the players extracted $5 * 11=55$ units which counts as more than $\mathbf{5 0}$ units. The common pool will not refill to 100 units. There is an $80 \%$ probability that there will be a Group 4 . If so, they receive a pool with 0 units. In that case, Groups 4 (and all future groups) cannot earn a bonus.

To make sure you understood the game, please answer the comprehension questions below.

YOU MUST ANSWER THESE QUESTIONS CORRECTLY TO BE ELIGIBLE TO RECEIVE YOUR BONUS FOR THIS HIT.

If one player proposes to extract 9 units, one player proposes 8 units, one player proposes 17 units, one player proposes 13 units and one player proposes 12 units, will the common pool refill to 100 units?

Yes, the common pool will refill (100 units).

$\mathrm{No}$, the common pool will not refill - it will be emptied to 0 units.

How likely is it that there will be another group?
$60 \%$
○ $80 \%$
$100 \%$

If your group extracted more than $\mathbf{5 0}$ units, can any future groups earn a bonus?
$\bigcirc$ Yes
No

Correct answers: 1) No (because $5 * 12$ units $>50$ ), 2) $80 \%$, 3) No. 


\section{Sample Instructions for Voting with Varied Parameters}

Threshold variation ( $T=40 \%$ is pictured here, $T=30 \%$ looks equivalent with adjusted values):

This HIT involves a sequence of groups. There is a common pool that is passed from one group to the next. This pool can be harvested to generate bonuses. If the pool is overexploited, it will be destroyed and subsequent groups cannot earn any bonuses.

Each group is made up of five people. You are in one of those groups.

You and the four other people in your group will each make a decision. Your decision determines the money you earn, and it can affect the potential earnings of all subsequent groups.

The common pool contains 100 units.

Each person in your group will take the same number of units out of the pool.

Each person proposes an amount to take out, between 0 and 20 units.

The five proposals are sorted from smallest to largest value.

The value in the middle is then selected: each of you extracts that amount.

For each unit you extract, you get a bonus of 5 cents.

If your group takes out a total of $\mathbf{4 0}$ units or less, the pool is refilled to 100 units.

If your group takes out a total of more than $\mathbf{4 0}$ units, the pool is permanently destroyed (set to 0 units). In this case none of the future groups can earn any bonus.

After your group has finished, there is an $80 \%$ chance that the common pool (refilled or destroyed) will be passed on to another group. There is a $20 \%$ chance that the study ends.

\section{Here is a summary of the game:}

In the beginning the common pool contains 100 units.

It is first given to Group 1. They make their decisions.

If Group 1 extracts 40 units or less, the pool refills to 100 units. Otherwise it goes to 0 units.

After Group 1, there is an $80 \%$ probability that there will be another group playing (Group 2). Group 2 can only earn a bonus if Group 1 passes on a pool that has refilled to 100 units. If Group 2 extracts 40 units or less, the pool refills to 100 units. Otherwise it goes to 0 units.

After Group 2, there is an $80 \%$ probability that there will be another group playing (Group 3). Group 3 can only earn a bonus if Group 2 passes on a pool that has refilled to 100 units. If Group 3 extracts 40 units or less, the pool refills to 100 units. Otherwise it goes to 0 units.

And so on:

After each group, there is an $80 \%$ probability that there will be another group. The next group can only earn a bonus, if the group before them did not extract more than 40 units. If a group extracts more than 40 units, then no subsequent group can earn a bonus. 
Here are two examples:

Example 1:

The five players in Group 1 propose to take out the following units: $8,6,5,16,10$. The values are sorted from smallest to largest $(5,6,8,10,16)$ and the middle value is selected: 8 . Together the players extracted $5^{*} 8=40$ units which counts as $\mathbf{4 0}$ units or less. The common pool will refill back to 100 units. There is an $80 \%$ probability that there will be a Group 2 . If so, they receive a pool with 100 units. In that case, Group 2 can earn a bonus.

Example 2:

The five players in Group 3 propose to take out the following units: 19, 20, 9, 3, 5. The values are sorted from smallest to largest $(3,5,9,19,20)$ and the middle value is selected: 11 . Together the players extracted $5^{*} 9=45$ units which counts as more than $\mathbf{4 0}$ units. The common pool will not refill to 100 units. There is an $80 \%$ probability that there will be a Group 4 . If so, they receive a pool with 0 units. In that case, Groups 4 (and all future groups) cannot earn a bonus.

To make sure you understood the game, please answer the comprehension questions below.

YOU MUST ANSWER THESE QUESTIONS CORRECTLY TO BE ELIGIBLE TO RECEIVE YOUR BONUS FOR THIS HIT.

If one player proposes to extract 10 units, one player proposes 8 units, one player proposes 17 units, one player proposes 6 units and one player proposes 12 units, will the common pool refill to 100 units?

Yes, the common pool will refill (100 units).

No, the common pool will not refill - it will be emptied to 0 units.

How likely is it that there will be another group?
$60 \%$
○ $80 \%$
$100 \%$

If your group extracted more than $\mathbf{4 0}$ units, can any future groups earn a bonus?

Yes

No

Correct answers: 1) No (because $5 * 10$ units $>40$ ), 2) $80 \%, 3$ ) No. 
Discount rate variation ( $\delta=0.7$ is pictured here, $\delta=0.6$ looks equivalent with adjusted values):

This HIT involves a sequence of groups. There is a common pool that is passed from one group to the next. This pool can be harvested to generate bonuses. If the pool is overexploited, it will be destroyed and subsequent groups cannot earn any bonuses.

Each group is made up of five people. You are in one of those groups.

You and the four other people in your group will each make a decision. Your decision determines the money you earn, and it can affect the potential earnings of all subsequent groups.

The common pool contains 100 units.

Each person in your group will take the same number of units out of the pool.

Each person proposes an amount to take out, between 0 and 20 units.

The five proposals are sorted from smallest to largest value.

The value in the middle is then selected: each of you extracts that amount.

For each unit you extract, you get a bonus of 5 cents.

If your group takes out a total of $\mathbf{5 0}$ units or less, the pool is refilled to 100 units.

If your group takes out a total of more than $\mathbf{5 0}$ units, the pool is permanently destroyed (set to 0 units). In this case none of the future groups can earn any bonus.

After your group has finished, there is an $70 \%$ chance that the common pool (refilled or destroyed) will be passed on to another group. There is a $30 \%$ chance that the study ends.

Here is a summary of the game:

In the beginning the common pool contains 100 units.

It is first given to Group 1. They make their decisions.

If Group 1 extracts 50 units or less, the pool refills to 100 units. Otherwise it goes to 0 units.

After Group 1, there is an $70 \%$ probability that there will be another group playing (Group 2). Group 2 can only earn a bonus if Group 1 passes on a pool that has refilled to 100 units.

If Group 2 extracts 50 units or less, the pool refills to 100 units. Otherwise it goes to 0 units.

After Group 2, there is an $70 \%$ probability that there will be another group playing (Group 3). Group 3 can only earn a bonus if Group 2 passes on a pool that has refilled to 100 units. If Group 3 extracts 50 units or less, the pool refills to 100 units. Otherwise it goes to 0 units.

And so on:

After each group, there is an $70 \%$ probability that there will be another group. The next group can only earn a bonus, if the group before them did not extract more than 50 units.If a group extracts more than 50 units, then no subsequent group can earn a bonus. 
Here are two examples:

Example 1:

The five players in Group 1 propose to take out the following units: $9,10,7,16,10$. The values are sorted from smallest to largest $(7,9,10,10,16)$ and the middle value is selected: 10 . Together the players extracted $5 * 10=50$ units which counts as $\mathbf{5 0}$ units or less. The common pool will refill back to 100 units. There is an $70 \%$ probability that there will be a Group 2 . If so, they receive a pool with 100 units. In that case, Group 2 can earn a bonus.

\section{Example 2:}

The five players in Group 3 propose to take out the following units: 19, 20, 8, 3, 11. The values are sorted from smallest to largest $(3,8,11,19,20)$ and the middle value is selected: 11 . Together the players extracted $5 * 11=55$ units which counts as more than $\mathbf{5 0}$ units. The common pool will not refill to 100 units. There is an $70 \%$ probability that there will be a Group 4 . If so, they receive a pool with 0 units. In that case, Groups 4 (and all future groups) cannot earn a bonus.

To make sure you understood the game, please answer the comprehension questions below.

YOU MUST ANSWER THESE QUESTIONS CORRECTLY TO BE ELIGIBLE TO RECEIVE YOUR BONUS FOR THIS HIT.

If one player proposes to extract 9 units, one player proposes 8 units, one player proposes 17 units, one player proposes 13 units and one player proposes 12 units, will the common pool refill to 100 units?

Yes, the common pool will refill (100 units).

$\mathrm{No}$, the common pool will not refill - it will be emptied to 0 units.

How likely is it that there will be another group?
$40 \%$
○ $70 \%$
$0100 \%$

If your group extracted more than $\mathbf{5 0}$ units, can any future groups earn a bonus?
Yes

$\mathrm{ONo}$

Correct answers: 1) No (because $12 * 5$ units > 50), 2) 70\%, 3) No. 


\section{Sample Instructions for Partial Voting}

Partial treatment (these also act as the "counter-balanced" second set of instructions that are presented after making a decision to all subjects in other conditions, see Section 2.2 for details):

This HIT involves a sequence of groups. There is a common pool that is passed from one group to the next. This pool can be harvested to generate bonuses. If the pool is overexploited, it will be destroyed and subsequent groups cannot earn any bonuses.

Each group is made up of five people. You are in one of those groups.

You and the four other people in your group will each make a decision. Your decision determines the money you earn, and it can affect the potential earnings of all subsequent groups.

The common pool contains 100 units.

$\mathbf{3}$ of the $\mathbf{5}$ people in your group will take the same number of units out of the pool. Those 3 people each propose an amount to take out, between 0 and 20 units.

The three proposals are sorted from smallest to largest value. The value in the middle is then selected: each of the 3 people extracts that amount.

The other 2 people in your group decide independently how many units (between 0 and 20 units) to extract. (They are not informed about the selected value of the other 3 people.)

For each unit you extract, you get a bonus of 5 cents.

If your group takes out a total of $\mathbf{5 0}$ units or less, the pool is refilled to 100 units.

If your group takes out a total of more than $\mathbf{5 0}$ units, the pool is permanently destroyed (set to 0 units). In this case none of the future groups can earn any bonus.

After your group has finished, there is an $80 \%$ chance that the common pool (refilled or destroyed) will be passed on to another group. There is a $20 \%$ chance that the study ends.

Here is a summary of the game:

In the beginning the common pool contains 100 units.

It is first given to Group 1. They make their decisions.

If Group 1 extracts 50 units or less, the pool refills to 100 units. Otherwise it goes to 0 units.

After Group 1, there is an $80 \%$ probability that there will be another group playing (Group 2).

Group 2 can only earn a bonus if Group 1 passes on a pool that has refilled to 100 units.

If Group 2 extracts 50 units or less, the pool refills to 100 units. Otherwise it goes to 0 units.

After Group 2, there is an $80 \%$ probability that there will be another group playing (Group 3).

Group 3 can only earn a bonus if Group 2 passes on a pool that has refilled to 100 units.

If Group 3 extracts 50 units or less, the pool refills to 100 units. Otherwise it goes to 0 units.

And so on:

After each group, there is an $80 \%$ probability that there will be another group. The next group can only earn a bonus, if the group before them did not extract more than 50 units.If a group extracts more than 50 units, then no subsequent group can earn a bonus. 
Here are two examples:

Example 1:

3 of 5 players in Group 1 propose to take out the following units: 10,14, 7. The values are sorted from smallest to largest $(7,10,14)$ and the middle value is selected: 10 . Each of the three players take out 10 units.

The other 2 players decide independently (without seeing the selected value) to take out the following units: 8,12 . Together all five players extracted $10+10+10+8+12=50$ units which counts as $\mathbf{5 0}$ units or less. The common pool will refill back to 100 units. There is an $80 \%$ probability that there will be a Group 2. If so, they receive a pool with 100 units. In that case, Group 2 can earn a bonus.

Example 2:

3 of 5 players in Group 1 propose to take out the following units: $17,8,11$. The values are sorted from smallest to largest $(8,11,17)$ and the middle value is selected: 11 . Each of the three players take out 11 units.

The other 2 players decide independently (without seeing the selected value) to take out the following units: 8,10 . Together all five players extracted $11+11+11+8+10=51$ units which counts as more than $\mathbf{5 0}$ units. The common pool will not refill to 100 units. There is an $\mathbf{8 0} \%$ probability that there will be a Group 4. If so, they receive a pool with 0 units. In that case, Groups 4 (and all future groups) cannot earn a bonus.

To make sure you understood the game, please answer the comprehension questions below.

YOU MUST ANSWER THESE QUESTIONS CORRECTLY TO BE ELIGIBLE TO RECEIVE YOUR BONUS FOR THIS HIT.

If one player proposes to extract 9 units, one player proposes 14 unit, and one player proposes 10 units, what proposal will be selected for these 3 players?
09
10
$\bigcirc 11$
O 14

In the example above, if the other 2 players extract 8 and $\mathbf{1 5}$

units respectively, will the pool refill?

Yes, the common pool will refill (100 units).

No, the common pool will not refill - it will be emptied to 0 units.

How likely is it that there will be another group?
$60 \%$
$80 \%$
$100 \%$

If your group extracted more than $\mathbf{5 0}$ units, can future groups earn a bonus?
Yes
No

Correct answers: 1) 10, 2) No (because 53 units > 50), 3) 80\%, 4) No. 


\section{References}

1. Holcombe, R. G. Public sector economics. (Wadsworth Pub. Co, 1987).

2. Deacon, R. \& Shapiro, P. Private preference for collective goods revealed through voting on referenda. The American Economic Review 65, 943-955 (1975).

3. Walker, J. M., Gardner, R., Herr, A. \& Ostrom, E. Collective choice in the commons: Experimental results on proposed allocation rules and votes. The Economic Journal 110, 212-234 (2000).

4. Putterman, L., Tyran, J.-R. \& Kamei, K. Public goods and voting on formal sanction schemes. Journal of Public Economics 95, 1213-1222 (2011).

5. Bernard, M., Dreber, A., Strimling, P. \& Eriksson, K. The subgroup problem: Voting on extractions from a common resource pool with varying degrees of polycentricity. Available at SSRN 1788798 (2011).

6. Camerer, C. Behavioral game theory. (Princeton Univ. Press, 2003).

7. Fischbacher, U., Gächter, S. \& Fehr, E. Are people conditionally cooperative? Evidence from a public goods experiment. Economics Letters 71, 397-404 (2001).

8. Kamei, K., Putterman, L. \& Tyran, J.-R. State or nature? Formal vs. informal sanctioning in the voluntary provision of public goods. Experimental Economics (In press).

9. Buhrmester, M., Kwang, T. \& Gosling, S. D. Amazon's Mechanical Turk A New Source of Inexpensive, Yet High-Quality, Data? Perspectives on Psychological Science 6, 3-5 (2011).

10. Amir, O. \& Rand, D. G. Economic games on the internet: The effect of \$1 stakes. PLoS One 7, e31461 (2012).

11. Horton, J. J., Rand, D. G. \& Zeckhauser, R. J. The online laboratory: Conducting experiments in a real labor market. Experimental Economics 14, 399-425 (2011).

12. Rand, D. G. The promise of Mechanical Turk: How online labor markets can help theorists run behavioral experiments. Journal of Theoretical Biology 299, 172-179 (2012).

13. Van der Heijden, E. C., Nelissen, J. H., Potters, J. J. \& Verbon, H. A. Transfers and the effect of monitoring in an overlapping-generations experiment. European Economic Review 42, 1363-1391 (1998).

14. Janssen, M. A., Holahan, R., Lee, A. \& Ostrom, E. Lab experiments for the study of social-ecological systems. Science 328, 613-617 (2010).

15. Milinski, M., Sommerfeld, R. D., Krambeck, H.-J., Reed, F. A. \& Marotzke, J. The collective-risk social dilemma and the prevention of simulated dangerous climate change. Proceedings of the National Academy of Sciences 105, 2291-2294 (2008).

16. Milinski, M., Semmann, D., Krambeck, H.-J. \& Marotzke, J. Stabilizing the Earth's climate is not a losing game: Supporting evidence from public goods experiments. Proceedings of the National Academy of Sciences 103, 3994-3998 (2006).

17. Tavoni, A., Dannenberg, A., Kallis, G. \& Löschel, A. Inequality, communication, and the avoidance of disastrous climate change in a public goods game. Proceedings of the National Academy of Sciences 108, 11825-11829 (2011).

18. Milinski, M., Röhl, T.\& Marotzke, J. Cooperative interaction of rich and poor can 
be catalyzed by intermediate climate targets. Climatic change 109, 807-814 (2011).

19. Jacquet, J. et al. Intra- and intergenerational discounting in the climate game. Nature Climate Change (2013). doi:10.1038/nclimate2024

20. Wade-Benzoni, K. A. A golden rule over time: Reciprocity in intergenerational allocation decisions. Academy of Management Journal 45, 1011-1028 (2002).

21. Wade-Benzoni, K. A. \& Tost, L. P. The egoism and altruism of intergenerational behavior. Personality and Social Psychology Review 13, 165-193 (2009).

22. Barrett, S. \& Dannenberg, A. Climate negotiations under scientific uncertainty. Proceedings of the National Academy of Sciences 109, 17372-17376 (2012).

23. Vasconcelos, V. V., Santos, F. C. \& Pacheco, J. M. A bottom-up institutional approach to cooperative governance of risky commons. Nature Climate Change (2013).

24. Ertan, A., Page, T. \& Putterman, L. Who to punish? Individual decisions and majority rule in mitigating the free rider problem. European Economic Review 53, 495-511 (2009).

25. The Economist Intelligence Unit. Democracy Index at http://www.eiu.com/public/topical_report.aspx?campaignid=DemocracyIndex 12 (2012).

26. WorldEnergy.org. Energy Sustainability Index at http://www.worldenergy.org/data/sustainability-index

27. World Bank. GDP Ranking at http://data.worldbank.org/data-catalog/GDPranking-table (2013).

28. Quandl.com. Quandl Data Browser at http://www.quandl.com (2014).

29. CIA World Factbook. Literacy at https://www.cia.gov/library/publications/theworld-factbook (2014).

30. World Health Organization. Life Expectancy at http://www.who.int/gho/mortality_burden_disease/life_tables/situation_trends/en (2013).

31. World Bank. WBI Governance \& Anti-Corruption at http:/web.worldbank.org/WBSITE/EXTERNAL/WBI/EXTWBIGOVANTCOR/0 ,,contentMDK:20788416 pagePK:64168445 piPK:64168309 theSitePK:1740530 ,00.html (2004). 


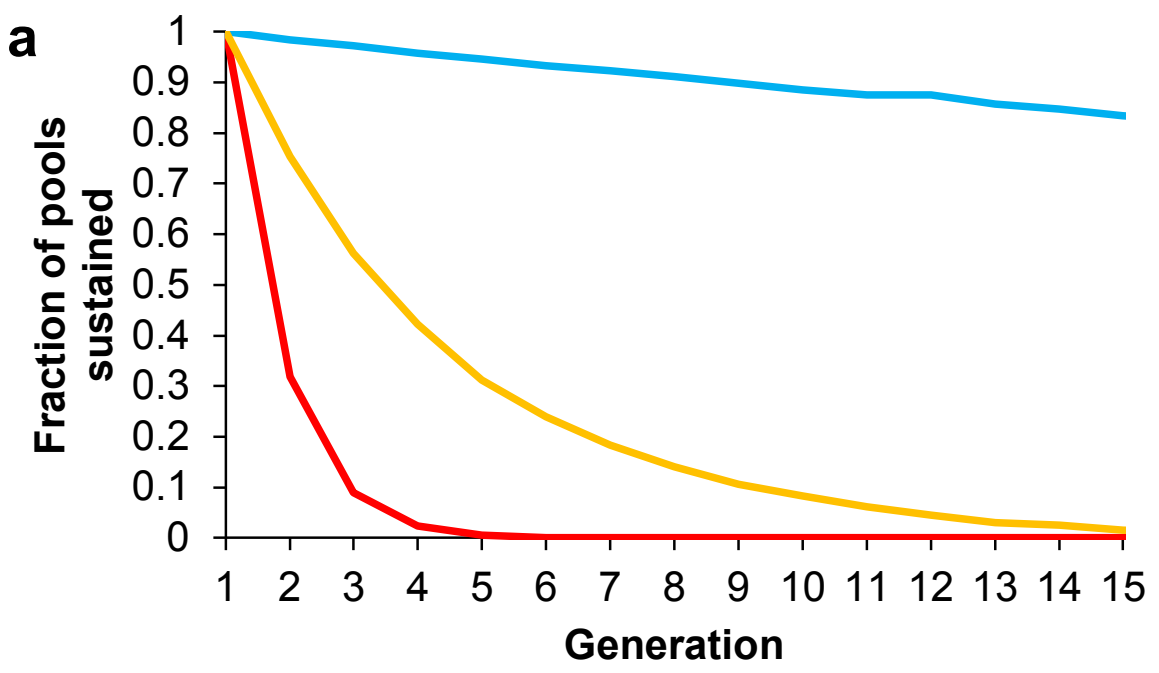

Unregulated

- Voting

Partial Voting

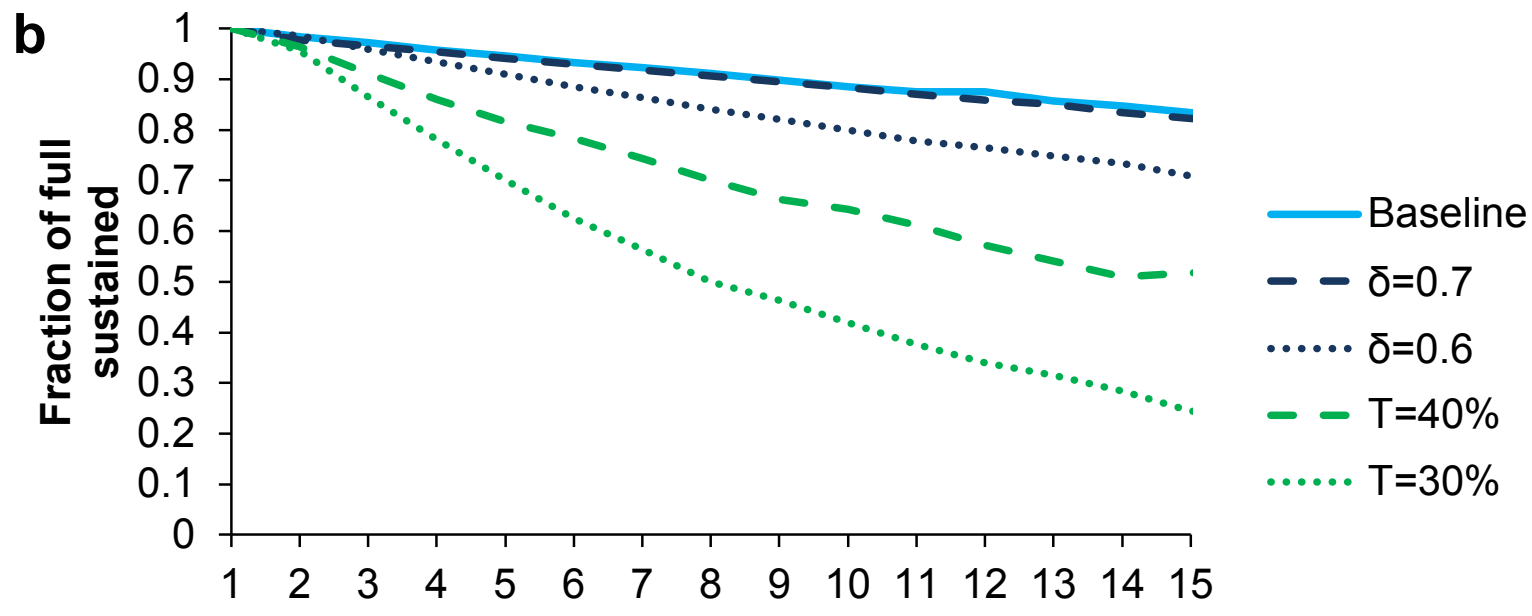

Generation 


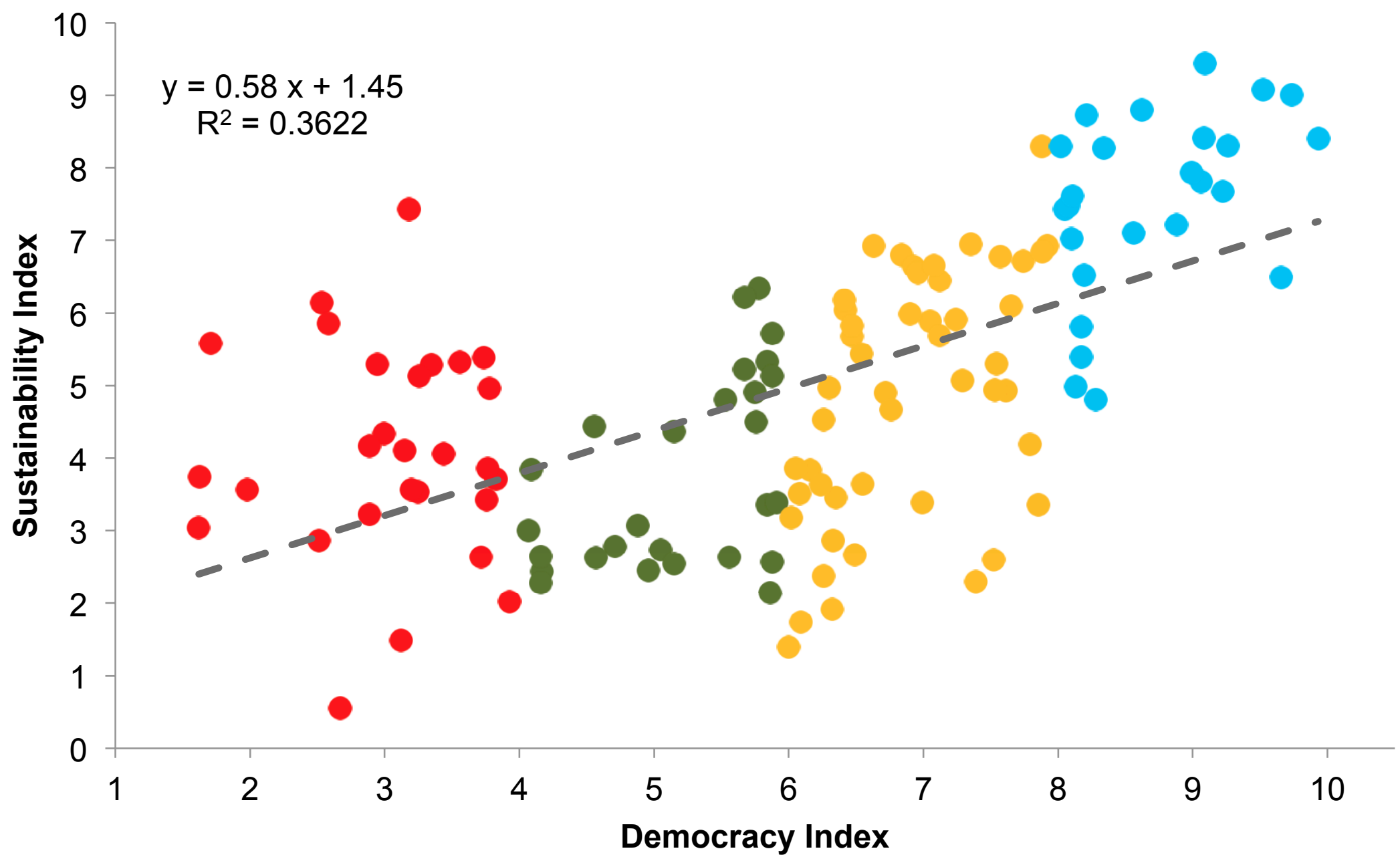

- Authoritarian Regimes • Hybrid Regimes $\bullet$ Flawed Democracies •Full Democracies 